Revue des patrimoines

\title{
Placer la première loi de planification urbaine (1919-1924) dans la réflexion actuelle : le cas de l'Auvergne
}

Contemporary approaches to France's earliest town-planning legislation (1919-1924): the case of the Auvergne department

\section{Bénédicte Renaud}

\section{OpenEdition}

Journals

Édition électronique

URL : https://journals.openedition.org/insitu/13754

DOI : 10.4000/insitu.13754

ISSN : $1630-7305$

Éditeur

Ministère de la Culture

\section{Référence électronique}

Bénédicte Renaud, «Placer la première loi de planification urbaine (1919-1924) dans la réflexion

actuelle : le cas de l'Auvergne », In Situ [En ligne], 30 | 2016, mis en ligne le 04 octobre 2016, consulté le 07 décembre 2022. URL : http://journals.openedition.org/insitu/13754 ; DOI : https://doi.org/10.4000/ insitu. 13754

Ce document a été généré automatiquement le 30 septembre 2020.

\section{(c) (†) $\odot$}

Creative Commons - Attribution - Pas d'Utilisation Commerciale - Pas de Modification 4.0 International - CC BY-NC-ND 4.0

https://creativecommons.org/licenses/by-nc-nd/4.0/ 


\section{Placer la première loi de planification urbaine (1919-1924) dans la réflexion actuelle : le cas de l'Auvergne}

Contemporary approaches to France's earliest town-planning legislation

(1919-1924): the case of the Auvergne department

Bénédicte Renaud

\section{Introduction. Allier planification urbaine et pittoresque 1}

D'après le géographe Christian Jamot, l'Auvergne « serait un excellent conservatoire des grands types [de villes] existantes [...] ». Le type classique y serait représenté : « de la plus petite (Ambert, Saint-Flour...) à la plus grande (Clermont) ; s'ajouterait un type industriel bien individualisé (Montluçon, Thiers...) et surtout un type tertiaire fort représenté aussi bien par la ville administrative (Moulins, Aurillac, Le Puy) que par la ville touristique (avec cette quintessence qu'est Vichy) [...]». Comprenons que les villes auvergnates constitueraient un échantillon représenta tif des villes françaises. Dans le type classique, poursuit $\mathrm{C}$. Jamot, « le noyau se caractérise par son tracé désordonné de rues » et un bâti composite, avec les exceptions que sont Riom et Montferrand, les extensions du XIX ${ }^{e}$ siècle feraient preuve de "visées urbanistiques étroites" et l'étalement plus récent ne se différencierait pas du processus observé ailleurs sur le territoire national ${ }^{2}$. Ce dernier point laisserait à penser que les villes d'Auvergne, dans un mouvement commun, auraient réagi à la manière de toutes les villes françaises aux préconisations étatiques du début du $\mathrm{xx}^{\mathrm{e}}$ siècle, moment où des lois sont promulguées qui tendent à dominer les nouvelles questions urbaines. 
2 En effet, le 14 mars 1919, à l'instigation du député Honoré Cornudet, est votée une loi qui oblige certaines villes françaises à se doter d'un « plan d'aménagement, d'embellissement et d'extension » (PAEE). Le texte de loi est modifié et complété le 19 juillet 1924. La loi vise des agglomérations de différents types: les villes de 10000 habitants et au-dessus, (les communes du département de la Seine), les communes en voie d'accroissement dont la liste aura été établie par le conseil général du département, celles qui auront demandé leur assujettissement à la loi, les «stations balnéaires, maritimes, hydrominérales, climatiques, sportives et autres, soumises à la taxe de séjour, dont la population augmente de $50 \%$ ou plus à certaines époques de l'année [...] et dont la liste sera établie par le préfet », les agglomérations "présentant un caractère pittoresque, artistique et historique, et inscrites sur une liste établie par les commissions départementales des sites et monuments naturels ".

3 Auparavant, en matière d'art urbain (le mot « urbanisme » n'existait pas encore), l'État était essentiellement intervenu en 1807 (une loi sur l'assèchement des marais dont un article imposait à toutes les villes de plus de 2000 habitants de se doter d'un plan d'alignement).

4 L'objet de la loi dite Cornudet est précisé dans une circulaire du 5 mars 1920, à laquelle est jointe une instruction concernant «les règles de nature à guider les municipalités dans l'application de la loi du 14 mars $1919 »^{3}$.

5 La législation française accusait un retard sur le sujet. Citons le député-maire d'une ville auvergnate, Paul Constans :

[...] c'est en 1903, en revenant d'un voyage en Belgique, en Allemagne et en Suisse que je me suis rendu compte de ce qu'il y avait d'avantageux dans une loi qui permet d'exproprier par zone et qui oblige les villes à avoir des plans d'ensemble, alors qu'en France nous étions toujours sous le régime de la loi de 1841 [réorganisant l'expropriation pour cause d'utilité publique] qui oblige souvent à payer une partie de la maison aussi cher que la maison entière. C'est en 1903 que le projet qui a abouti à la loi du 14 mars 1919 a été déposé par le citoyen Delory et moi $^{4}$

6 On peut considérer qu'après la mise en place des Plans d'aménagement régionaux (1935), la loi du 2 février 1941 (qui réorganise les services de l'urbanisme) et la loi d'urbanisme du 15 juin 1943, qui rebaptise notamment les plans (devenus simples "plans d'aménagement»), la loi dite Cornudet devient progressivement caduque. Mais elle connaît une longue descendance : les Plans de reconstruction et d'aménagement (en zone bombardée) à partir de 1940, les Plans d'urbanisme directeurs à partir de 1958, les SDAU (Schéma directeur d'aménagement urbain) et les POS (Plan d'occupation des sols) à partir des années 1960, les PLU (Plan local d'urbanisme), les PADD (Plan d'aménagement et de développement durable) et les SCOT (Schéma de cohérence territoriale) des années 2000, en témoignent.

7 En 1920, les instructions peuvent se regrouper autour de deux axes principaux, le fonctionnel d'un côté, le cadre de vie de l'autre. Le député Cornudet présentait « sa » loi à partir de trois thèmes : esthétique, hygiène et circulation. Pour un thésard contemporain d'Honoré Cornudet, il s'agissait notamment de tenir compte des masses populaires qui ont évolué et «n'ignorent plus ce qui est beau ${ }^{5}$ ». Viviane Claude résume, quant à elle : il s'agissait «d'allier la planification à ce qu'on appelait le pittoresque ${ }^{6}$ ». Sur le premier point, on peut lire dans l'ouvrage d'Amédée Bonde paru en 1927 que la loi se voulait une arme contre l'extension chaotique des villes de France. Il ajoute : « C'est donc surtout par 
les lotisseurs que les plans et programmes d'extension et d'aménagement devraient être exécutés $»^{7}$.

Figure 1

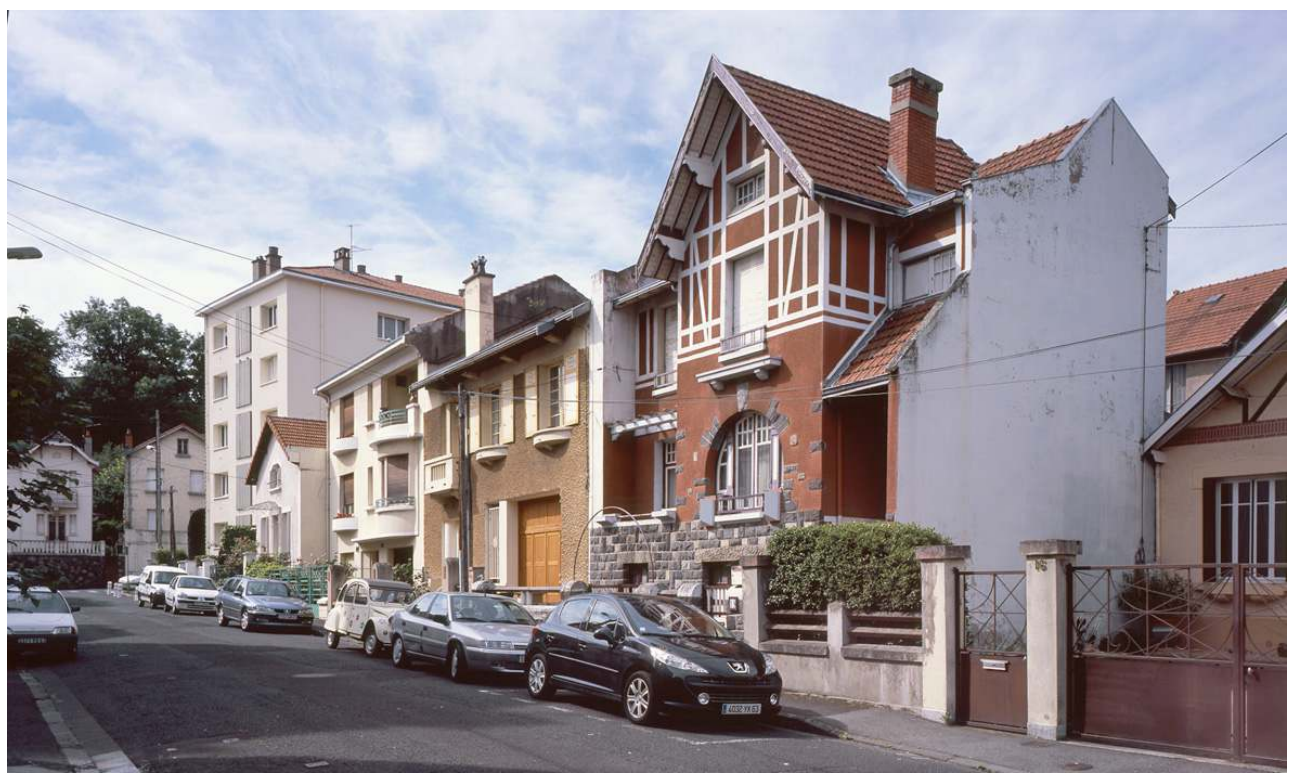

Chamalières (Puy-de-Dôme), rue Émile-Zola (programmée sur le PAEE de 1930), « maisons en retrait derrière des jardins à l'alignement », telles que préconisées dans I'Instruction générale de la loi.

Phot. Périn, Jean-Michel. @ Région Auvergne-Rhône-Alpes, Inventaire général, ADAGP, 2010.

Dans les instructions de 1920, chaque municipalité concernée est invitée à "être raisonnable », tout en ayant des "vues suffisamment larges »; plus précisément, elles sont invitées à prévoir de larges voies « avec des pentes minimes, des angles ouverts, des rayons de giration amples, des visées suffisantes facilitées par de larges pans coupés ", de "s'attaquer bien plus énergiquement aux cours obscures qu'aux rues étroites ", de mettre «beaucoup plus d'arbres et beaucoup moins d'habitants ", de favoriser «les maisons en retrait derrière des jardins à l'alignement et les jardins en général " (fig. 1), d'étudier « les emplacements destinés aux monuments, édifices et services publics » et de ménager les monuments existants (si faire se peut, y abriter les services publics); puis on les met en garde contre «le danger des dégagements malencontreux qui ont désencadré et dénudé si bêtement trop de chefs-d'œuvre de l'architecture nationale [...]», il faut également "distribuer largement aux habitants l'eau potable et l'eau de lavage", « organiser un réseau d'égouts avec les pentes et les lavages nécessaires », « donner aux populations le goût de l'hygiène, de la propreté, de la tenue de leur ville [...] », etc.

(a) l'embellissement n'était pas abordée de front dans un chapitre spécifique mais les interférences entre ce domaine-là et le fonctionnel, en matière de paysage urbain notamment, sont inévitables : prévoir des jardins de façade dans un règlement n'a pas pour but exclusif d'introduire des allées fleuries en ville ${ }^{8}$, cela revient aussi à éloigner les maisons les unes des autres de part et d'autre de la rue, de façon à faire entrer plus largement le soleil et à faire circuler l'air (deux éléments purificateurs et régénérants).

Par ailleurs, la question du zonage n'était pas directement évoquée dans les instructions, mais l'absence de prévision par zone est un des principaux motifs de refus des dossiers, en Auvergne en tout cas. 
11 Les documents à fournir à l'administration (plans indiquant les créations et les modifications, programme déterminant les servitudes hygiéniques, archéologiques et esthétiques, projet d'arrêté du maire réglant les conditions d'application des uns et de l'autre) devaient être visés par une commission départementale puis par une commission supérieure, après avoir fait l'objet d'une enquête publique, d'une délibération du conseil municipal et de rapports pour chacune des commissions. Les questions d'alimentation en eau et d'assainissement étaient plus précisément examinées par les membres de la commission supérieure siégeant au conseil supérieur d'hygiène publique (à partir de 1930, des règlements sanitaires départementaux sont mis en place). Le Conseil d'État devait finalement provoquer l'avis de l'administration des Beaux-Arts, via la Commission supérieure des monuments historiques à partir de 1930, toutes les fois qu'un nombre significatif de monuments protégés étaient signalés dans la ville ${ }^{9}$. L'obtention d'une déclaration d'utilité publique signifiait l'aboutissement de l'opération.

En 1940, à l'échelle de la France entière, 1938 communes étaient concernées par la confection d'un PAEE, dont 273 avaient vu le jour et 158 étaient en préparation ${ }^{10}$.

Ces quelques prescriptions et orientations nous renvoient assez fidèlement à certains traits de notre environnement actuel. Il semble même que nous touchions ici aux origines de certains maux que les édiles actuels ont à gérer (comme le zonage, qui deviendra zonage purement fonctionnel un peu plus tard).

Saisir le groupe des villes auvergnates à cet instant (l'entre-deux-guerres) revient à dresser un état des lieux au moment où l'urbanisme de plan, autrement dit la planification urbaine (aménager l'existant et prévoir l'agrandissement), prend forme en France avec l'État comme incitateur. Les municipalités étant invitées à fournir des « idées directrices » aux « hommes de l'art » qu'elles doivent nommer, les plans et mémoires explicatifs devant être approuvés, pour commencer, par le conseil municipal, ils montrent comment les villes - de manière contrainte certes - se projettent dans l'avenir. À l'échelle nationale, la loi proprement dite est réputée avoir eu peu d'effet immédiat (si l'on compte le nombre de déclarations d'utilité publique prononcées), mais les échanges qu'elle a suscités entre pouvoirs locaux et pouvoir central, et parfois entre édiles et habitants, obligeant les uns et les autres à se positionner, aident à comprendre où se situaient les enjeux locaux et par là, à entrer dans le processus de fabrication des villes en Auvergne.

15 Bien sûr, il ne s'agit pas de réduire les comportements des villes au domaine des intentions conscientes mais, dès ce stade, la récurrence en Auvergne de certaines réactions municipales peut être mise en évidence, de même que des singularités.

Malgré la difficulté, pleinement relevée par Viviane Claude, qu'il y a à rassembler la documentation sur le sujet, il faut donc tenter de faire le point: en termes de simple décompte, d'abord, puis en tentant de repérer les traces laissées dans les plans et paysages urbains ${ }^{11}$. Ensuite, la part faite au "pittoresque» sera notamment mise en lumière : la notion est en effet particulièrement attirante en ce qu'elle a à voir avec celle de patrimoine, et pour le recoupement que l'on peut faire avec cette caractéristique morphologique plusieurs fois mise en évidence pour les villes auvergnates, voire du Massif central, "d'espace urbain très rarement organisé ${ }^{12}$ ", de noyau "caractérisé par [un] tracé désordonné de rues ${ }^{13}$ » ou encore "d'immobilité des centres historiques, [...objet de] très rares recompositions ${ }^{14}{ }^{\prime}$. 


\section{Le décompte pour l'Auvergne et la vie des dossiers}

17 Les fonds consultés jusqu'à présent ont permis de rassembler plusieurs éléments significatifs, sans pouvoir établir un bilan complet et arrêté. Les fonds des archives des quatre départements ne sont pas classés de la même manière et ce qu'il a été possible d'exhumer de la série $M$ (administration générale et économie) dans le Puy-de-Dôme ${ }^{15}$ n'a pas été retrouvé du tout dans les trois autres départements, dans cette série ou ailleurs ${ }^{16}$. Aux Archives nationales ont été consultées des listes des agglomérations concernées par la loi et, au Centre des archives contemporaines de Fontainebleau, des dossiers émanant du ministère de l'Intérieur et du ministère de l'Équipement existent mais seulement pour certaines villes. À la médiathèque du Patrimoine ont été retrouvées essentiellement des généralités concernant la gestion des dossiers de PAEE par la Commission supérieure des monuments historiques. De plus, la présence de dossiers, aux archives départementales, municipales ou nationales, ne permet pas forcément de connaître toutes les étapes de la procédure : certains plans manquent, d'autres projets ne sont connus qu'à travers les rapports destinés aux Commissions, voire très indirectement par le biais des seules réactions des habitants lors de l'enquête publique. La documentation réunie est donc inégale, disparate et lacunaire. Pour un cas, ni les archives nationales, ni départementales, ni municipales n'ont livré de plan, et c'est seulement grâce au fait que Bellerive-sur-Allier constituait le sujet de thèse de Jean Descoutures qu'une version du projet a été retrouvée à l'Institut d'urbanisme de Paris ${ }^{17}$. Plusieurs fonds municipaux restent à explorer ${ }^{18}$.

\section{Vingt-neuf villes de quatre types différents}

Cependant, on peut avancer sans grand risque d'erreur que 29 agglomérations en Auvergne ont été visées par la loi Cornudet. Neuf l'ont été au titre des « 10000 habitants ou au-dessus ${ }^{19}$ ", sept étaient jugées « en voie d'accroissement $»^{20}$, dix étaient classées stations thermale ${ }^{21}$ ou climatique ${ }^{22}$ (ou mixte ${ }^{23}$ ), et trois avaient demandé et obtenu leur assujettissement à la loi ${ }^{24}$. Bizarrement, aucune localité en Auvergne n'avait été retenue par la commission départementale des sites dans la catégorie des agglomérations à " caractère pittoresque, historique ou artistique ${ }^{25}$ ".

Sur les 29, huit ont fini par obtenir (entre 1923 et 1936) la déclaration d'utilité publique : Bellerive-sur-Allier (qui avait demandé son assujettissement), Cusset (considérée comme en voie d'accroissement), Néris-les-Bains, Chamalières, Châtel-Guyon, (stations thermales) ${ }^{26}$, Aurillac et Clermont-Ferrand (population dépassant 10000 habitants) ${ }^{27}$. En règle générale, entre le premier envoi de projet et la déclaration d'utilité publique, le délai est d'environ deux ans ${ }^{28}$. La déclaration d'utilité publique les autorisait à mettre en place des servitudes de différentes natures si nécessaire, à opposer le plan aux lotisseurs en les obligeant à inscrire leur projet de voirie dans le tracé du PAEE, et dans certains cas à obtenir des subventions pour la confection des plans puis pour l'exécution des aménagements. Les PAEE pouvaient être financés par le produit de la taxe de séjour que les stations thermales et climatiques étaient autorisées à percevoir pour les affecter obligatoirement à des travaux d'assainissement et d'embellissement.

En pendant des villes "ayant demandé leur assujettissement », on pourrait faire figurer celles qui se sont montrées récalcitrantes et que les préfets ont dû relancer à une ou 
plusieurs reprises : Riom prétend en 1935 ne pas répondre au critère des 10000 habitants, ce à quoi le préfet répond que depuis le recensement de 1931, elle peut se prévaloir de 11042 habitants, et que par ailleurs la ville pourrait être visée au titre de son caractère artistique $^{29}$; le PAEE d'Issoire est en cours d'étude en 1930 puis encore en $1940^{30}$; pour Saint-Yorre, le sous-préfet fait savoir au maire en 1927 que, moyennant un accord du conseil municipal, l'agglomération pourrait figurer sur la liste des villes tenues de produire un plan d'embellissement: l'accord est obtenu, le conseil municipal reconnaissant que des «obligations d'embellissement » commencerait «par l'adduction d'eau potable » (sic), un homme de l'art est désigné (Mazon), mais le PAEE proprement dit n'aboutira pas et sera remplacé, étrangement, par un plan d'alignement et de nivellement, que l'on doit au géomètre Lombardy, approuvé par le préfet en $1933^{31}$; le conseil municipal de Saint-Éloy-les-Mines ne décide de mettre le projet à l'étude qu'au cours de l'année 1931; à la même date, Ceyrat et Thiers n'ont pas encore entamé la procédure $^{32}$; au Chambon-sur-Lignon, le maire fait savoir au conseil municipal en 1922 que le classement en station touristique est conditionné à la mise au point d'un "plan d'alignement, d'aménagement et d'extension » (sic), puis la station est classée sans qu'on ait trace de la réalisation d'un plan ${ }^{33}$. De Moulins, nous connaissons la présentation écrite et détaillée qui en a été faite au conseil municipal le 18 mars $1922^{34}$, mais ensuite nous ne retrouvons sa trace que pour apprendre qu'il a été retourné à la mairie "pour être complété » au $1^{\mathrm{er}}$ avril 1927, et encore en 1928 et 1929. Certaines villes ont renâclé mais ont fini par produire les documents (Royat, dont le projet a été couronné d'une DUP (déclaration d'utilité publique) en $1935^{35}$, Beaumont, dont le projet datant de 1939 a été vu une première fois par la Commission supérieure la même année, mais a fini par être ajourné « jusqu'au retour des armées de son auteur ${ }^{36} »$ ). D’autres ont abandonné en cours d'instruction comme Montluçon, après trois retours de dossiers, entre 1929 et 1938, avec avis défavorable de la Commission supérieure ${ }^{37}$, ou Commentry qui renonce officiellement en 1938, après être passée sous la barre des 10000 habitants $^{38}$. Des abandons sans explication peuvent probablement s'expliquer aussi par des changements d'équipe municipale lors des élections de 1925.

\section{Auteurs des projets et avis des commissions}

21 Quels sont les «hommes de l'art» auxquels les villes auvergnates ont fait appel? Le métier d'urbaniste naît seulement en 1911 avec la création de la Société française des

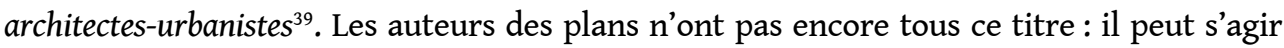
d'architectes, d'ingénieurs ou de géomètres. Sur les 25 projets pour lesquels nous avons des noms d'auteurs, ou d'équipes, huit professionnels sont issus de bureaux d'études d'urbanisme parisiens ${ }^{40}$, vingt sont de la région ${ }^{41}$, six sont d'origine inconnue mais plus probablement des locaux. La proportion est presque la même à l'échelle nationale (échantillon de 85 villes) : V. Claude faisait remarquer la préférence des élus pour les compétences locales à $75 \%$.

Notons que le projet de l'ingénieur Mercier pour Néris-les-Bains a reçu les félicitations de la Commission supérieure (DUP du 12 décembre 1923); de même, le rapporteur Louis Bonnier demande qu'on félicite la municipalité de Cusset, pour avoir accepté l'importance du réseau de voies prévues (par le bureau Topoplan, DUP du 14 janvier 1936) (fig. 2). Par ailleurs, certains projets ont été considérés comme trop hardis, d'autres trop timides, ce 
qui a pu motiver un avis défavorable de la Commission supérieure, qui se rangeait en général à l'avis du rapporteur ${ }^{42}$, mais pas obligatoirement.

Figure 2

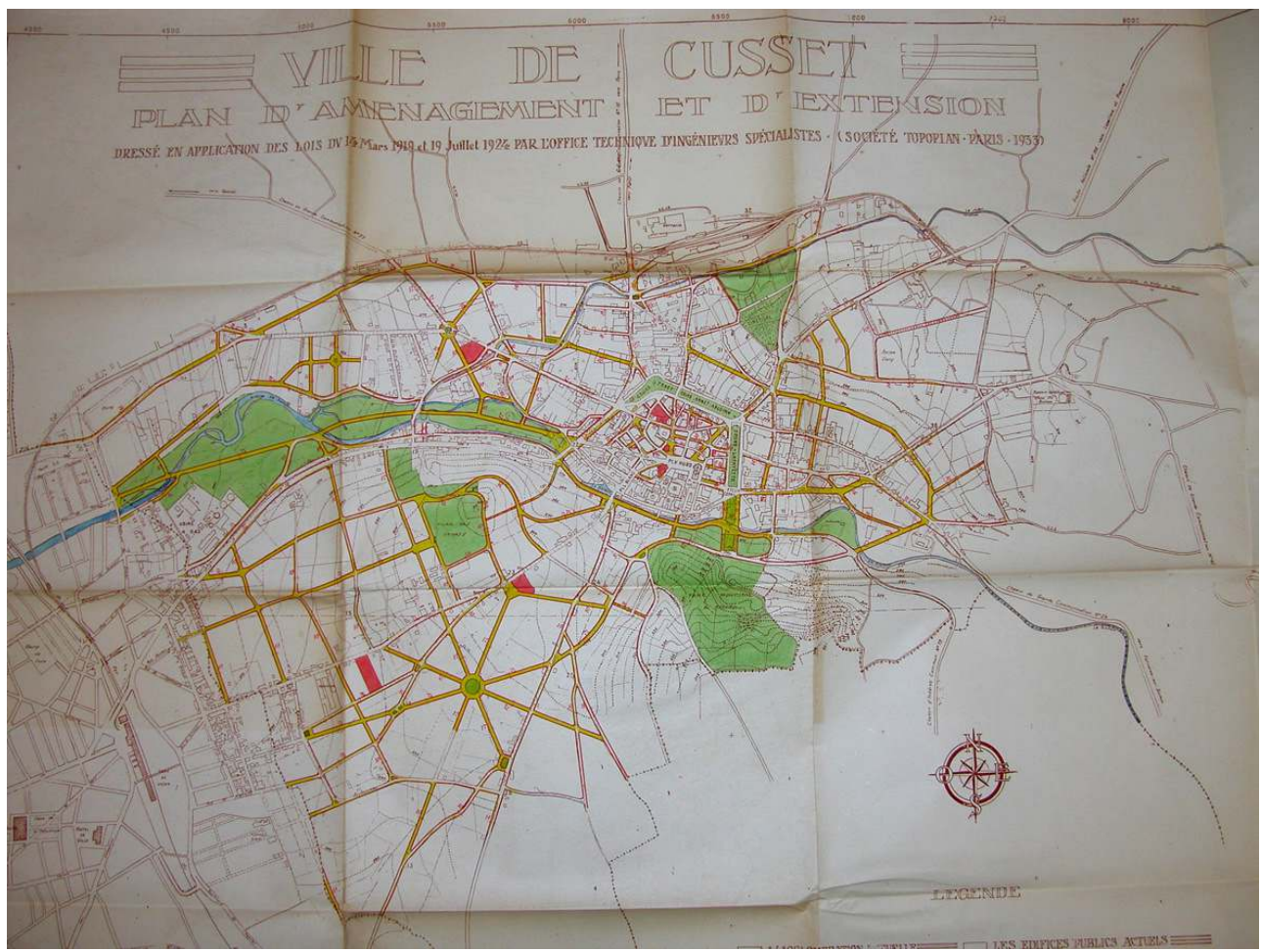

Cusset (Allier), «Plan d'aménagement et d'extension », société Topoplan, 1933. Centre des archives nationales de Fontainebleau, versement 19790426, article 42.

Phot. Renaud, Bénédicte. (c) Région Auvergne-Rhône-Alpes, Inventaire général, ADAGP, 2010.

Les projets de Commentry et Vichy figurent dans la seconde catégorie, des «trop timides »: il leur est reproché notamment de ne pas avoir assez franchement aligné (fig. 3). Pour Louis Bonnier, en 1938, quand un élargissement franc est prévu, un certain nombre de propriétaires atteints préfèrent émigrer en périphérie «ce qui est un phénomène heureux et constaté en urbanisme » : l'État, à travers le rapporteur Bonnier, prône donc l'étalement urbain ${ }^{43}$. Il peut leur être reproché aussi de ne pas donner aux habitants «l'espoir de vivre un jour dans une ville plus gaie, plus saine et plus spacieuse » (" aucune cité-jardin, aucun square, aucun espace planté n'est prévu pour aérer ou égayer une ville qui n'offre à ses habitants que la vue assez morose des hautes cheminées ou des crassiers d'usine »): en effet, seules des opérations ponctuelles ont été prévues à Commentry (reconstruction d'une école de garçons, agrandissement d'une école maternelle, restauration de l'hôtel de ville, construction d'un marché) ${ }^{44}$, ce qui est contraire à l'esprit de la loi. 


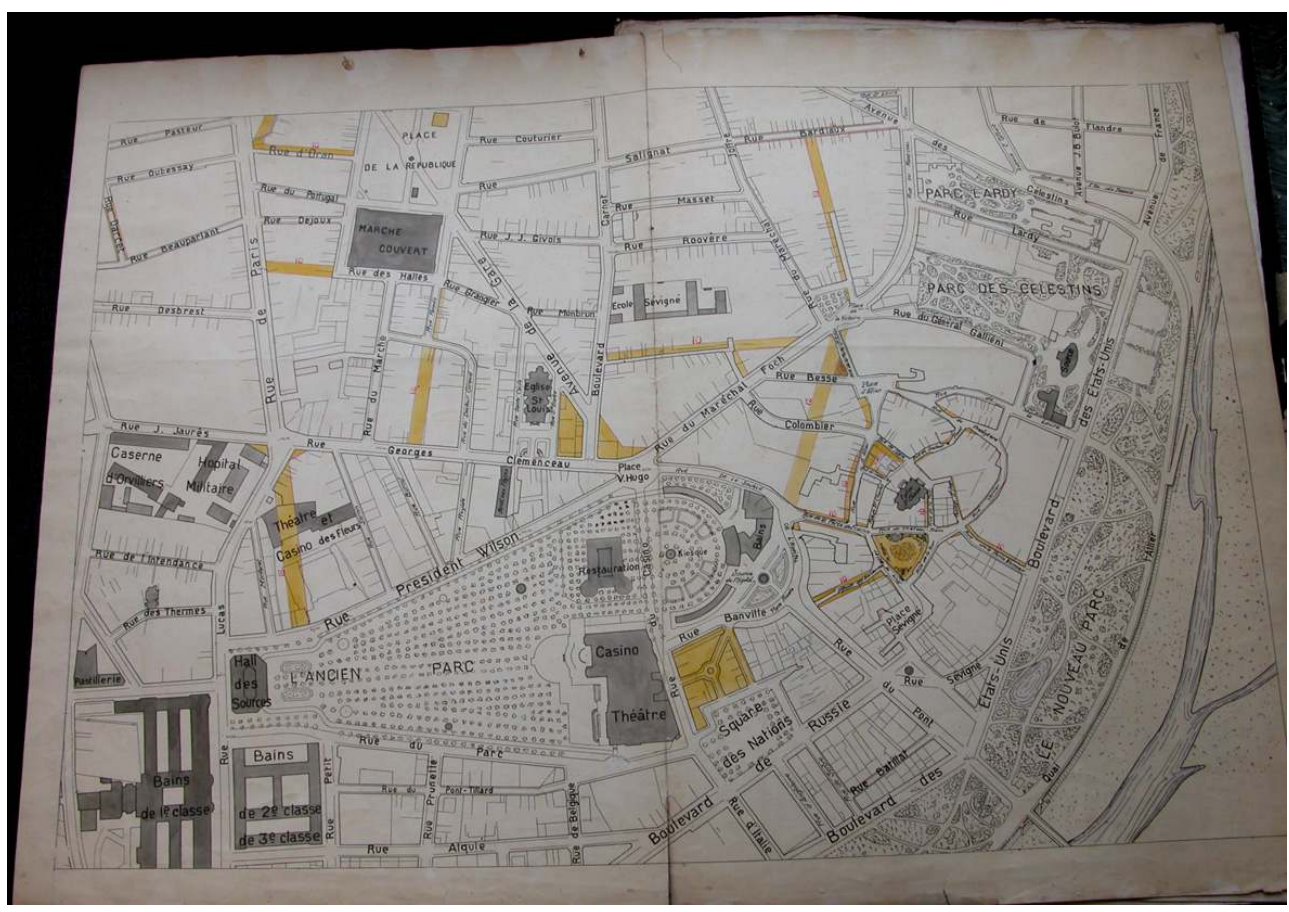

Vichy (Allier), «Plan d'extension et d'embellissement de la ville de Vichy », planche 8, détail, I.A. Passignat, ingénieur-voyer, 14 mars 1928. Médiathèque de Vichy, fonds patrimoniaux, non coté. Phot. Renaud, Bénédicte. @ Région Auvergne-Rhône-Alpes, Inventaire général, ADAGP, 2010.

Pour Vichy, trois plans avaient été soumis à Letrosne (comme si l'idée d'un concours à lancer plutôt qu'une simple commande, émise en 1918, avant même la promulgation de la loi, ne pouvait pas être abandonnée), les plans A, B et C. Seul le plan A a été retrouvé à la médiathèque de Vichy ${ }^{45}$, mais c'est le plan $\mathrm{C}$, celui de l'architecte Mazon, établi aux frais de la Compagnie fermière, qui a retenu l'attention du rapporteur, le plan A étant qualifié de « très insuffisamment étudié, des transformations souhaitables pour une ville telle que Vichy n'y figur[a]nt pas $^{46} »$; puis, en 1938, Bérard trouve que le plan est trop sommaire pour se faire une opinion sérieus $\mathrm{e}^{47}$ (il faut attendre la grande campagne de révision des plans d'aménagement des années 1940 pour que l'urbaniste et théoricien vichyssois Gaston Bardet soit amené à faire officiellement des propositions pour sa ville) ${ }^{48}$. De plus, A. Bérard faisait observer que le plan de voirie avait été établi en fonction de la gare : il est donc obsolète, "car la locomotion automobile a ses exigences ", et le plan n'a pas été retravaillé en ce sens : il faudrait maintenant prévoir des voies d'évitement, des parcs de stationnement et des « sorties vers les sites magnifiques de l'Auvergne ».

Les projets d'Aubière (fig. 4, fig. 5), Montluçon et Aurillac sont jugés trop hardis mais les deux premières villes n'obtiendront jamais leur DUP, contrairement à la troisième (dès 1926). À Aubière, les $28 \mathrm{~km}$ de voirie créés ou modifiés étaient démesurés par rapport au nombre d'habitants (3500), la liaison avec Clermont n'était pas assez bien envisagée et Ernest Pincot, de la commission départementale, jugeait aussi que les places et rues devaient être élargies "plus modérément». Le conseil municipal avait cependant maintenu les options prises dans le projet, au motif, par exemple, que la plupart des voies nouvelles et élargissements prévus ne reprenaient que ceux du plan d'alignement de 1874 : « doit-on se montrer moins hardi dans les prévisions que nos grands-pères [...] ? », 
lit-on dans un procès-verbal de délibération ${ }^{49}$. Accessoirement, cette observation montre que les plans peuvent s'enchaîner suivant une certaine logique (à Clermont, le plan d'alignement de 1859 avait été globalement repris dans le PAEE et quand Gaston Bardet remet son projet de révision de PAEE en 1949, il prévoit un plan «d'étude de voirie pouvant être conservée du plan de $1925^{50}$ "; à Beaumont, le plan d'alignement de la rue Saint-Verny daté de 1936 n'avait pas reçu le moindre début d'exécution en 1938 quand le PAEE est mis en chantier : l'agent voyer l'incorpore alors à ce dernier ${ }^{51}$ ). À la Commission supérieure, Bérard avait repris l'argument de la liaison défectueuse avec Clermont et concluait, en 1940, sur la nécessité de créer un groupement d'urbanisme autour de Clermont, «une des régions les plus pittoresques de France ${ }^{52}$ ». Les choses se sont arrêtées là pour Aubière. Il faut reconnaître que le géomètre Weissbrodt, dirigé en principe par l'équipe municipale, avait taillé assez brutalement dans les tissus anciens, à coup de curetage d'îlots insalubres, de percements, et avec un aménagement monumental de deux places liées et régulières, englobant l'église et la mairie. Le maire d'Aubière apparait comme un fervent partisan de la planification en matière de voirie au motif qu'il ne faut pas se trouver plus tard dans la nécessité d'ouvrir les rues «à grands frais, au milieu de propriétés bâties "; en plus, si on lui objecte que des plans de la ville existent, il répond qu'ils sont partiels, à réactualiser, à rattacher ensemble et à compléter. En revanche, l'aménagement de l'existant ne représente pas un argument pour lui.

Figure 4

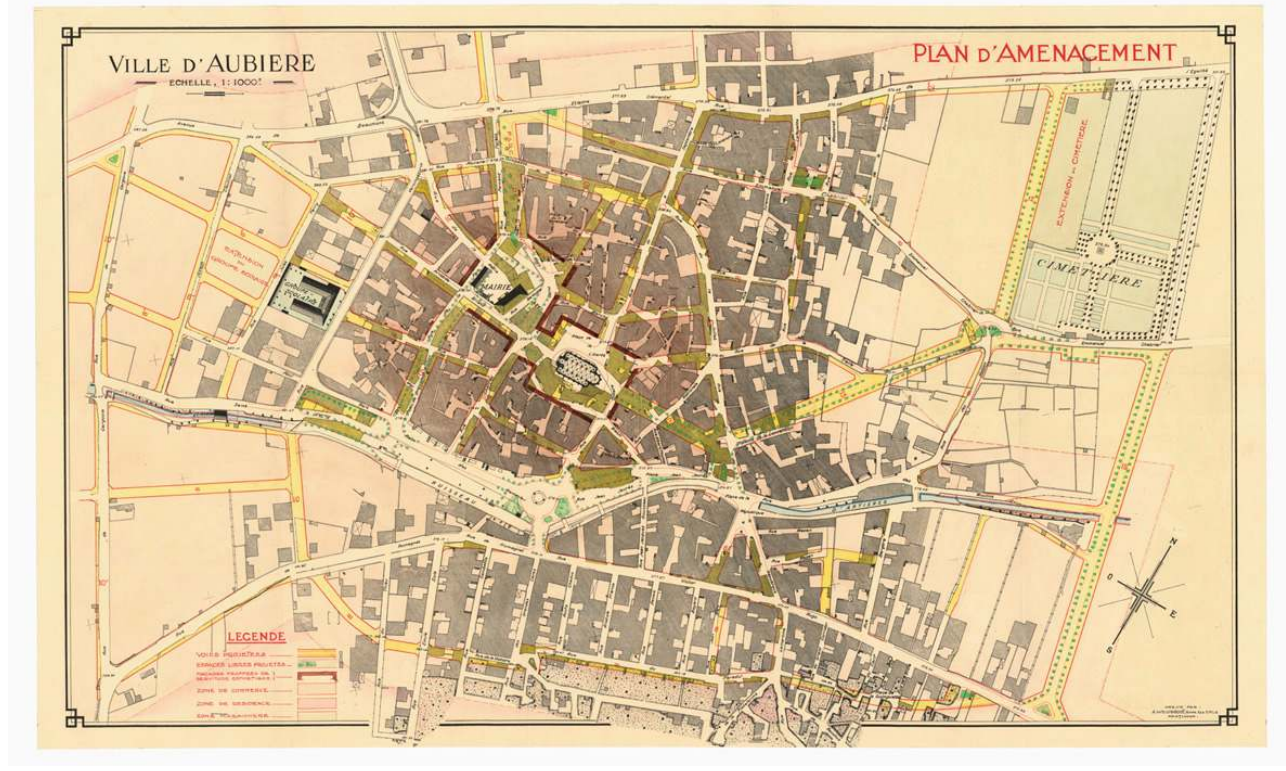

Aubière (Puy-de-Dôme), « Dossier d'aménagement, d'embellissement et d'extension », plan d'aménagement, Weissbrodt, géomètre-expert, [1938]. Archives départementales du Puy-de-Dôme, M 60832. (http://archivesdepartementales.puydedome.com).

Repro. Da Costa-Vigne. (c) Archives départementales du Puy-de-Dôme, 2010. 


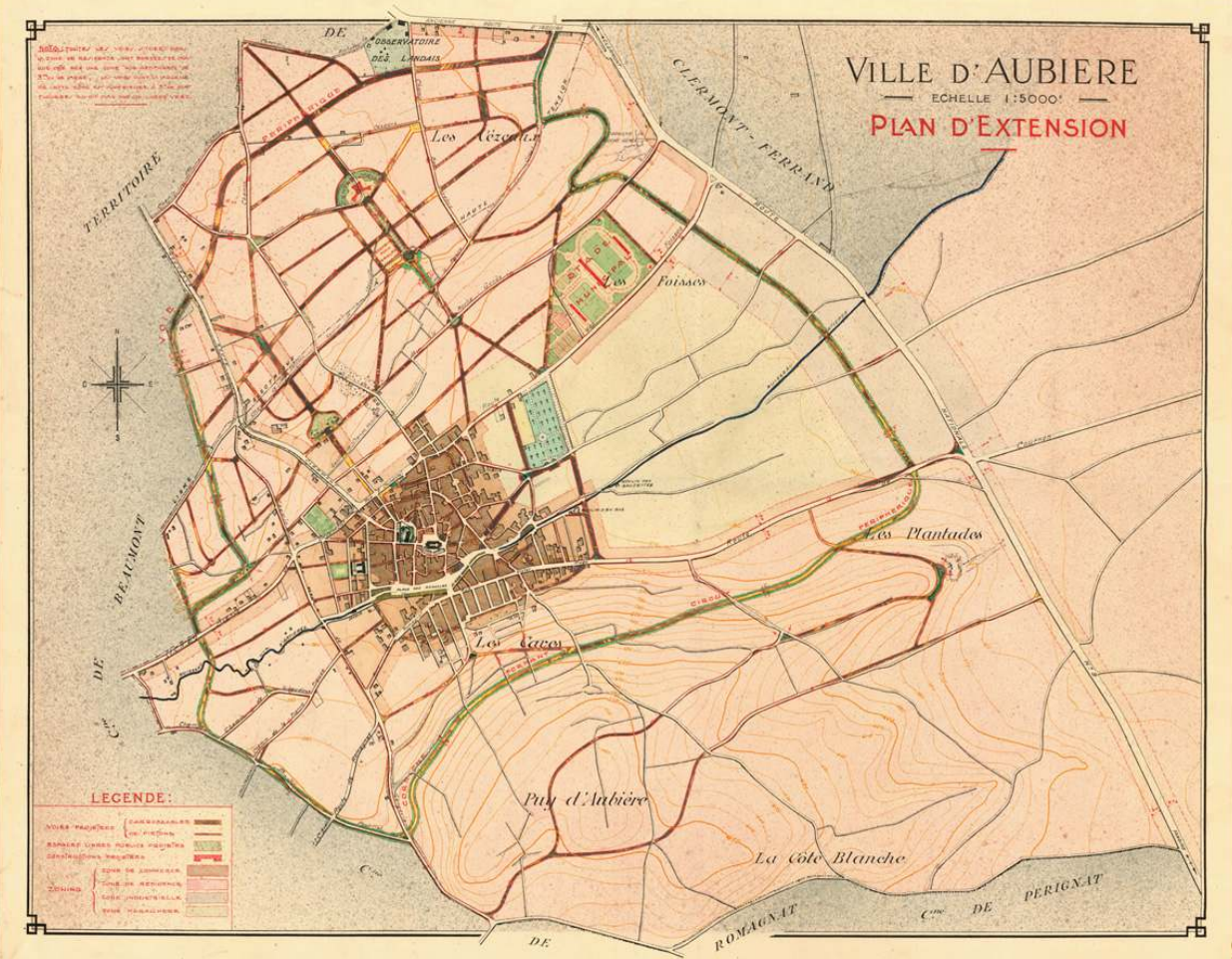

Aubière (Puy-de-Dôme), « Dossier d'aménagement, d'embellissement et d'extension », plan d'extension, Weissbrodt, géomètre-expert, [1938]. Archives départementales du Puy-de-Dôme, M 60832 (http://archivesdepartementales.puydedome.com).

Repro. Da Costa-Vigne. (c) Archives départementales du Puy-de-Dôme, 2010.

Quant à Aurillac, l'exagération de certains aspects du projet n'était notée qu'en pendant à des éloges, ce qui amoindrissait la critique en lui donnant simplement valeur de mise en garde ou de conseil (en effet, il arrivait parfois que l'avis favorable de la Commission supérieure soit assorti de quelques mises en garde ou de recommandations). La prévision d'extension était jugée excessive (la superficie de la ville était doublée !) mais le conseil municipal, en 1924, se défendait : il fallait mettre en valeur le site merveilleux d'Aurillac qui allait « devenir une station de villégiature de premier ordre ${ }^{53}$ ». Et la municipalité, forte de cette ambition, avait imaginé implanter grands hôtels et casino sur les hauteurs de la ville (d'où l'on peut parfois apercevoir le massif cantalien) : ce projet nécessitait la création d'aménagements d'envergure, qui ne seront jamais réalisés, malgré l'obtention de la déclaration d'utilité publique. La Ville s'était probablement, malgré tout, rangée à l'avis du rapporteur Normand sur ce point comme sur celui d'une cité-jardin ouvrière qui avait été jugée "mal composée », ainsi que sur celui de l'élargissement excessif de la rue des Forgerons, puisque tout cela ne fut pas réalisé. Dès 1944, la révision du plan était demandée, celui-ci étant alors beaucoup moins défendu et qualifié « d'inapplicable ${ }^{54}$ ».

Le dossier de Montluçon était repassé trois fois devant la Commission supérieure. Chaque fois, l'avis du rapporteur Bonnier avait été suivi. La première fois, le dossier était refusé parce que l'on démolissait complètement la vieille ville sauf le château, qu'on ne prévoyait pas d'extension et que les courbes de niveau ne figuraient pas sur le plan. La deuxième fois, il manquait des raccords avec les agglomérations limitrophes, et Bonnier s'inquiétait aussi de prescriptions architecturales dangereuses (un "type déterminé» 
d'immeuble pour le faubourg, le risque de "faux vieux» pour le centre ancien); la troisième fois, c'était la visibilité trop réduite d'une fourche, les élargissements limités à 8 et $10 \mathrm{~m}$ et jamais à 12 , ainsi que l'imprécision sur les surfaces des espaces libres qui avaient justifié le refus du projet.

Bien sûr, des manquements en matière d'hygiène pouvaient aussi concourir à la sanction d'un avis défavorable : à Vichy par exemple en 1938, il est observé que le règlement sanitaire remonte à 1909, ce qui n'est " plus en harmonie avec une hygiène moderne » et on demande à l'édilité de s'inspirer du règlement sanitaire départemental à l'usage des stations thermales ${ }^{55}$.

\section{Le rôle de la population, individus et associations}

Quant aux habitants, pris individuellement ou regroupés sous forme d'associations ou de signataires de pétitions, la parole leur est donnée dans l'enquête publique obligatoire. Mais aussi, le chargé de projet de Saint-Nectaire énonce clairement qu'on compte sur «l'expression de leur imagination » dans le fleurissement et l'utilisation des espaces de reculement de façade (imposés) ${ }^{56}$ !

D'une manière plus générale, c'est-à-dire dans le cadre limité d'un plan ponctuel d'alignement de rue, ou dans le cas d'un PAEE, les habitants ont la possibilité de participer à la fabrication de la ville en cédant gratuitement les terrains sujets à l'alignement ${ }^{57}$.

31 Dans certains cas, le procès-verbal d'enquête n'enregistre aucune observation, à Nérisles-Bains, par exemple ${ }^{58}$.

Les récriminations des habitants, que l'on connait dans certains cas parce que les résultats des enquêtes ont été conservés, peuvent prendre un caractère anecdotique (qui gêne Viviane Claude pour son analyse nationale) mais leur portée n'est pas insignifiante et leur évocation n'est pas inutile à l'heure où des tentatives de démocratie participative en matière d'urbanisme se multiplient. Ce phénomène, d'ailleurs, n'était pas nouveau : le droit de pétition donné aux habitants avait abouti à ce que l'emplacement de la halle au blé soit celui préconisé par les Riomois (Puy-de-Dôme) à la fin du xviII siècle, par les Maursois (Cantal) au début du XIXe , aux dépens du choix des municipalités ${ }^{59}$.

3 À Royat, une pétition de 105 signataires manifestait une opposition au projet de création du grand parc central, prenant probablement modèle sur Vichy, dont le parc des Sources apparait comme le centre de la ville, mais qui nécessitait le transfert de la poste sur les hauteurs de la ville : ces deux aspects du projet ont cependant été réalisés ${ }^{60}$.

Au Mont-Dore, on répertorie huit interventions différentes lors de l'enquête publique de 1925, les unes tenant en peu de mots et émanant d'un seul individu (qu'un établissement de bains-douches soit prévu : projet adopté en conseil municipal, mais jamais réalisé), ou ayant fédéré un groupe d'habitants (que l'artère principale débutant à la gare soit prolongée jusqu'à l'autre extrémité de la ville menant au Sancy est une proposition signée de 11 personnes, à laquelle il ne sera pas donné suite pour des raisons financières); une autre intervention, plus importante (un mémoire de deux pages recto-verso ${ }^{61}$ rédigé par la propriétaire de deux grands hôtels), s'organise en critiques, contre-propositions et suggestions. Une des critiques porte sur la hauteur des façades, limitée à $15 \mathrm{~m}$ à la corniche, qui est jugée " arbitraire et ne donnant lieu qu'à une uniformité banale »; il est proposé que la Dordogne «donne lieu, dans le passage du parc, à des arrangements par 
bassins et cascades » ou bien qu'elle soit recouverte afin d'obtenir plus d'espace pour le parc: les deux solutions sont écartées au motif des dépenses "somptuaires" qu'elles susciteraient, etc. L'idée de profiter du passage de la Dordogne de manière à l'intégrer au paysage urbain était pourtant intéressante, mais elle n'a jamais été suivie. Le plan du projet dont il est question en 1925 pourrait être celui de Léon Jaussely ${ }^{62}$, mais plus sûrement celui de l'Union urbaniste qui s'était substitué à lui (fig. 6).

Figure 6

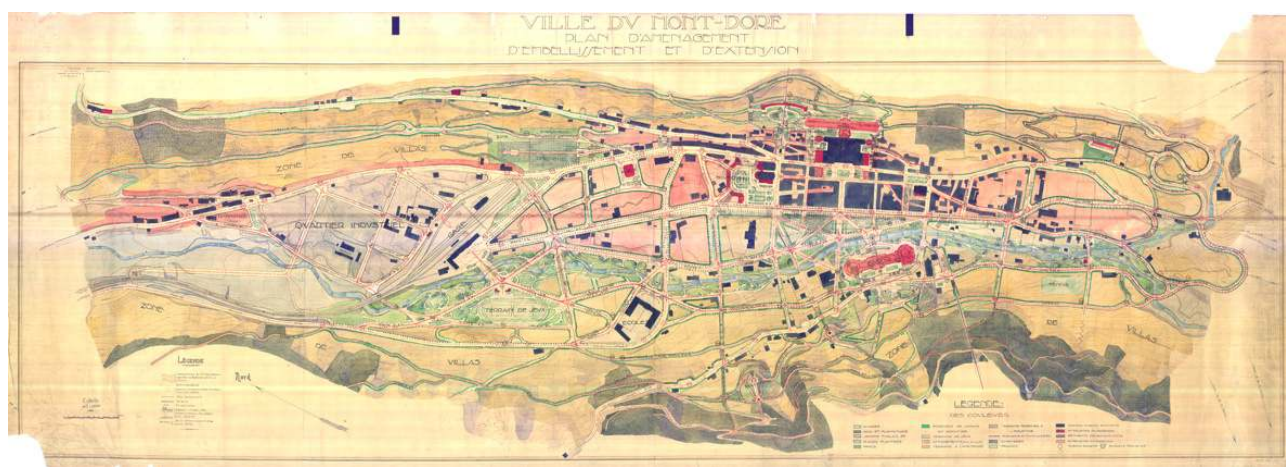

Le Mont-Dore (Puy-de-Dôme). «Plan d'aménagement, d'embellissement et d'extension », Léon Jaussely, s. d.

(c) Centre des archives d'architecture du XXe siècle, fonds Léon Jaussely, collections Académie d'architecture, Paris

À Chamalières, le PAEE de 1930 comprend la création d'une place aux abords de l'école privée Sainte-Thècle (fig. 7). Ce projet de place suscite un débat vif, et intéressant par certains aspects, au moment de l'enquête de commodo et incommodo ${ }^{63}$. Une pétition est lancée grâce à la rédaction de quatre formulaires différents distribués aux habitants. Dans le premier est invoqué le caractère semi-rural de la localité : « l'espace, l'air et la lumière n'y manquent point et la création d'une place publique ne s'impose pas du point de vue de l'hygiène. En particulier, le quartier qui entoure l'emplacement indiqué par le plan est très bien aéré et se compose surtout de maisons ou villas avec jardins ». Dans le deuxième formulaire, il est question des « vastes parcs publics ou privés disséminés sur le territoire de la commune » qui « constituent d'immenses réservoirs d'air pur». En outre, pour le cas où la place servirait à accueillir marchés ou foires, «la proximité immédiate de Clermont, ville de plus de cent dix mille âmes, rend la création, la réussite d'un marché à Chamalières absolument improbable ». Dans le troisième formulaire on lit :

dans Chamalières, comme emplacement de place publique, un seul endroit convient, est central, est indiqué par l'histoire et la carte de la ville : c'est l'avenue de Royat aux alentours de l'arrêt des trams, de l'hôtel des postes, de l'hôtel de ville [qui a changé de place entre-temps], de la place de l'église [...]. Une place publique déjà s'y fait; qu'on s'avise de l'agrandir [...]. Le centre nerveux, le centre commercial de Chamalières est dans ce périmètre, ce serait mauvaise manœuvre que d'essayer de le transporter ailleurs [ «il n'est au pouvoir de personne de le déplacer ", lit-on aussi dans un des formulaires] [...]. Nous faisons en fait et nous ferons de plus en plus partie de Clermont. 


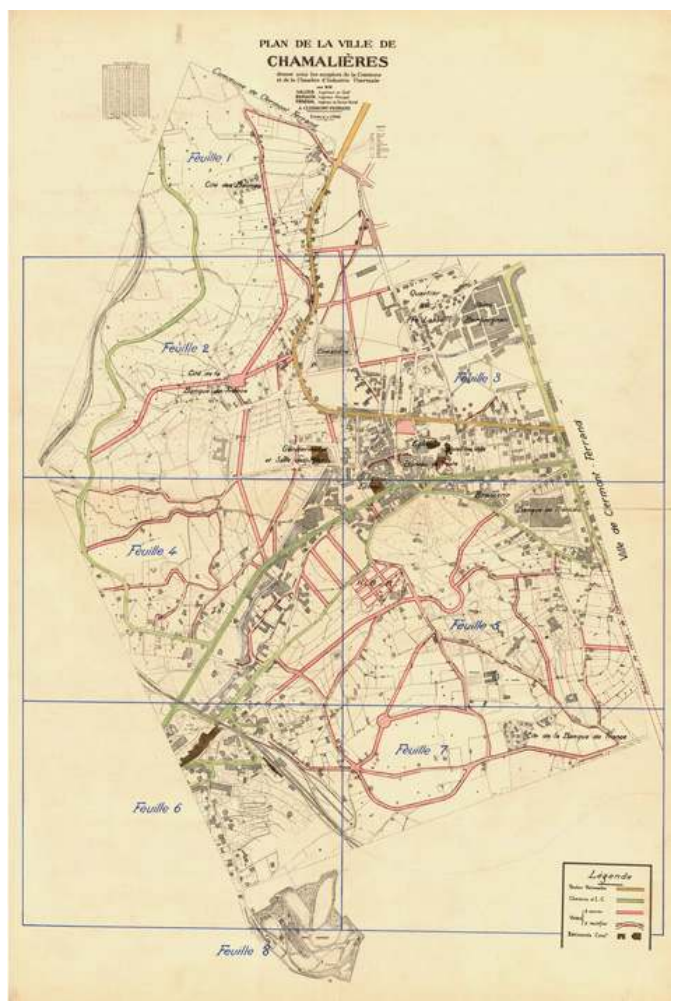

Chamalières (Puy-de-Dôme), «Plan d'extension et d'aménagement », Vaurs, ingénieur en chef, Férérol, ingénieur principal, Bergoin, ingénieur du service vicinal, 29 août 1930. Archives départementales du Puy-de-Dôme, M 60846. Le projet de place publique apparaît sous la forme du rectangle rose situé en bordure d'une avenue, à proximité du noyau urbain. C'est l'emplacement actuel de l'extension de l'école Sainte-Thècle donnant sur l'avenue Joseph-Claussat (http:// archivesdepartementales.puydedome.com).

Repro. Da Costa-Vigne. (c) Archives départementales du Puy-de-Dôme, 2010.

On note ici que le site sélectionné dans le PAEE était lui aussi limitrophe de l'église et dans les environs de l'ancien hôtel de ville. La mairie répond par ailleurs que l'espace choisi est déjà libre, n'étant occupé que par des jardins maraîchers, contrairement à celui préconisé par les protestataires sur lequel s'élèvent des immeubles [depuis lors, celui-ci a été libéré]. Le projet donne lieu, malgré les 643 signatures recueillies (sur 8000 habitants), au décret d'utilité publique du 15 mars 1932. Ce dernier fait néanmoins l'objet d'un pourvoi devant le Conseil d'État par une société immobilière intéressée par l'agrandissement de l'école. Le pourvoi est rejeté le 11 juillet 1933. Mais aujourd'hui on constate que l'école a bien été agrandie (comme le réclamaient les protestataires) et occupe le site prévu au PAEE pour la place publique. Ainsi peut-on s'interroger: les quelque 600 protestataires étaient-ils plus visionnaires que leurs élus ? Ces derniers témoignaient-ils d'un esprit de concurrence ou d'indépendance plus vif vis-à-vis de Clermont? Ou bien, le vrai but étaitil d'empêcher l'école privée de s'agrandir ? Le curé de la ville avait écrit au préfet qu'il se trouvait face «à une grosse difficulté que lui suscite une municipalité maçonnisante ${ }^{64}$ " (en joignant à sa lettre la pétition de 80 anciens combattants). Un changement d'équipe municipale aurait alors conduit à la transformation du projet. L'enquête est à poursuivre. Mais ces conflits-là contribuent aussi, bien évidemment, à fabriquer la ville.

À Châtel-Guyon, il a suffi de la réclamation d'un seul propriétaire pour que les dimensions et l'orientation d'une place soient modifiées sur le projet $^{65}$. 
La municipalité du Puy-en-Velay se heurte deux fois de suite aux protestations de la population, à la suite de la présentation du premier projet en 1922 puis du deuxième en 1934. Au point que le maire prend des mesures transitoires en déclarant en 1935 que «ce plan ne [doit] pas être avant longtemps déclaré d'utilité publique [...] ${ }^{66} »$. Pour Le Puy-enVelay, nous disposons des « Observations présentées à l'enquête de commodo et incommodo ouverte à la mairie du Puy sur le projet d'aménagement, d'embellissement et d'extension de la ville du Puy par la Commission des amis du vieux Puy [... $]^{67}$ ». Dans ce texte, les Amis $\mathrm{du}$ vieux Puy font leurs les préconisations de la Commission des sites qui sont alors retranscrites. Il en ressort notamment ce constat d'une vieille ville trop sacrifiée, cet étonnement : "que des voies en général moins larges soient prévues dans la ville neuve que pour les percées à travers la ville ancienne ». Et les Amis du vieux Puy ajoutent :

Dans ces quartiers à peu près morts et d'un accès qui sera toujours difficile la question de la circulation des voitures n'est point capitale [...], il est bien incontestable que ce ne sont point de grandes voies modernes mais tout le pittoresque de notre ville ancienne que viennent voir les touristes, point de vue que nous livrons à la méditation de certains de nos compatriotes qui, pour faciliter

l'accès de la vielle ville aux touristes, commenceraient par la démolir.

On pourrait éventuellement confronter la réflexion des habitants du Puy-en-Velay sur le centre initial de leur ville, constitué de "quartiers à peu près morts » qu'il n'est pas nécessaire de réveiller, à la considération des Chamaliérois sur le leur qu'il «n'est au pouvoir de personne de déplacer »: on pourrait, dans la première, trouver une illustration de l'idée du théoricien italien contemporain, Gustavo Giovannoni (1843-1947), qui préconisait en 1913 de transformer les centres anciens « en modeste[s] quartier[s] mixte[s], associant commerces et logements non luxueux» et de déplacer ainsi les centres-villes car, écrivait-il, les nouvelles fonctions, les nouveaux impératifs urbains ne pourront jamais s'adapter à l'ancien cadre ${ }^{68}$. Édouard Joyant, dans son traité d'urbanisme de 1923, reprenait cette proposition : « dans certains cas, on ne doit pas moderniser cette partie centrale » (bien avant donc que les Plans de sauvegarde et de mise en valeur soient institués en France, en 1962). L'histoire des villes, pour le moment, a plutôt retenu la seconde proposition, plus « rossiennne », qui consiste à se fixer éternellement autour des " éléments premiers ${ }^{69}$ ». Il faut constater néanmoins qu'au Puy, le centre administratif et commercial s'était déjà déplacé dans le bas de la ville (à partir de $1819^{70}$ ). Les centres peuvent donc bien être déplacés ou dédoublés ; la bipolarité (sous forme de " ville haute " et « ville basse ») serait même une des caractéristiques des villes du Massif central ${ }^{71}$.

L'alternative " centre immuable "géographiquement" mais bouleversé, "dénaturé" au gré des impératifs qui évoluent» / "centre ancien préservé "patrimonialement" mais relégué dans un statut de quartier secondaire » est vivace. Il faut encore ajouter d'autres partis possibles, comme «centre patrimonial revivifié par la réhabilitation et la réutilisation respectueuse ». Ces enjeux restent d'actualité.

\section{Les plans « Cornudet » : pour un seul type de ville? Pour quelles réalisations en Auvergne?}

41 Si la loi avait été rigoureusement et inexorablement appliquée, toutes les villes entrant dans les catégories prédéfinies auraient-elles eu le même visage ? Douze plans vont nous permettre de répondre, ainsi que quelques éléments de programme. Les plans de quatre villes « recalées » (Aubière, Beaumont, La Bourboule et Saint-Nectaire) ont été conservés 
et étudiés : ils seront pris en compte en tant que tels dans l'analyse ${ }^{72}$. Volontairement, nous n'avons pas isolé les villes thermales des autres catégories d'agglomérations dans nos comparaisons car elles étaient concernées au même titre que les autres dans l'instruction générale de 1920. À l'échelle nationale, Philippe Duboy et Bernard Toulier ont fait observer, d'une part que les villes d'eaux et les stations balnéaires constituent les laboratoires d'expérimentation de nouvelles formes d'urbanisme durant le xix siècle (et, pourrions-nous ajouter, préparent ainsi à la rédaction de cette instruction) ${ }^{73}$, d'autre part, qu'elles sont les plus attentives à faire appliquer la loi.

\section{Regard panoramique sur les plans}

Des « reconductions $»^{74}$ schématiques ont été menées systématiquement (annexe 1). Elles illustrent notre propos. Nous ne reviendrons pas en détail sur chacune des opérations réalisées : pour huit voire douze villes, le travail serait de trop grande ampleur, avec entre autres la difficulté de faire la part des projets surajoutés qui demanderait d'avoir reconstitué l'historique fin de chacun des aménagements des villes concernées depuis 1940. En revanche, en se limitant à l'ossature de la ville que représente la voirie, des comparaisons deviennent possibles.

\section{Voir Annexe 1 : Réalisations, des reconductions schématiques}

En procédant de manière "panoramique », il est facile de se rendre compte qu'il n'y a pas un plan-type Cornudet. Bien sûr, l'existant à partir duquel les "hommes de l'art» travaillent n'a jamais la même forme. Mais en plus, les «figures urbaines » utilisées dans les espaces vierges ou les réaménagements, comme des figures de style, ne sont pas les mêmes d'un plan à l'autre. Pour prendre deux extrêmes, les tracés sinueux de la voirie caractérisent notamment le projet d'Aurillac, à la manière d'un immense parc paysager (fig. 8), tandis qu'à Clermont-Ferrand règne une juxtaposition de damiers quelle que soit la configuration physique, plutôt accidentée, des différents secteurs de la commune (fig. 9).

Figure 8

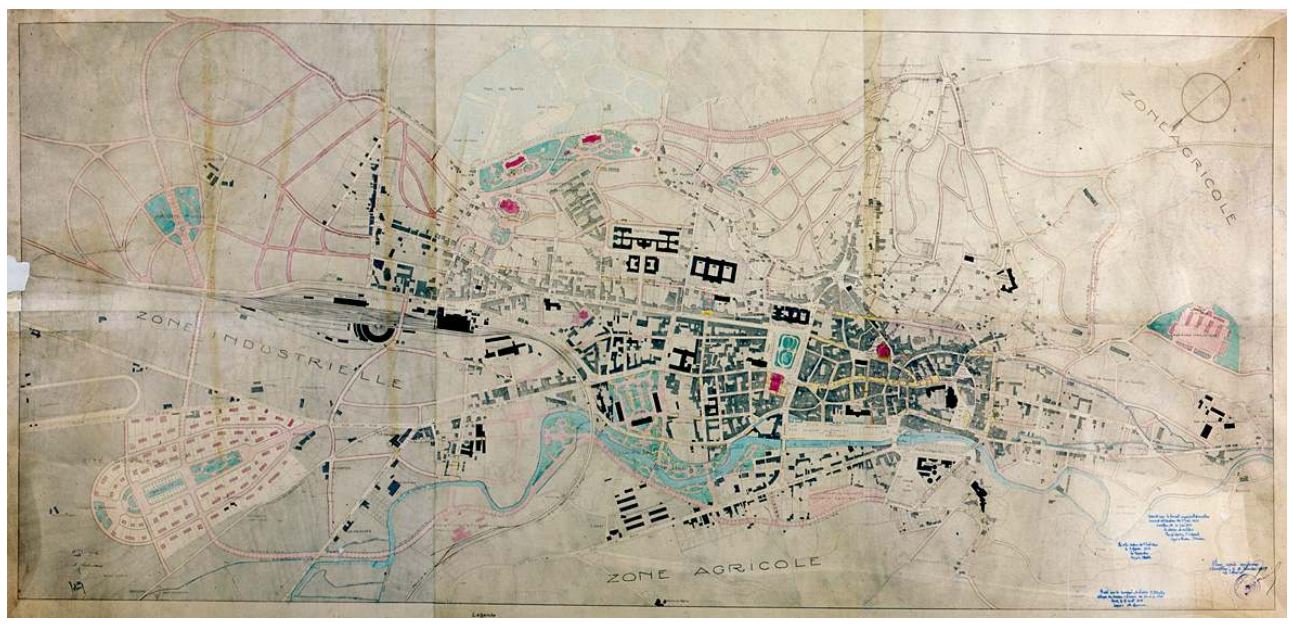

Aurillac (Cantal), Plan d'aménagement, d'embellissement et d'extension, Union urbaniste, Terrisse et Croizet, architectes, 1922. Archives départementales du Cantal, 1 Fi 13 (http://archives.cantal.fr). Phot. Périn, Jean-Michel. @ Région Auvergne-Rhône-Alpes, Inventaire général, ADAGP, 2009. 


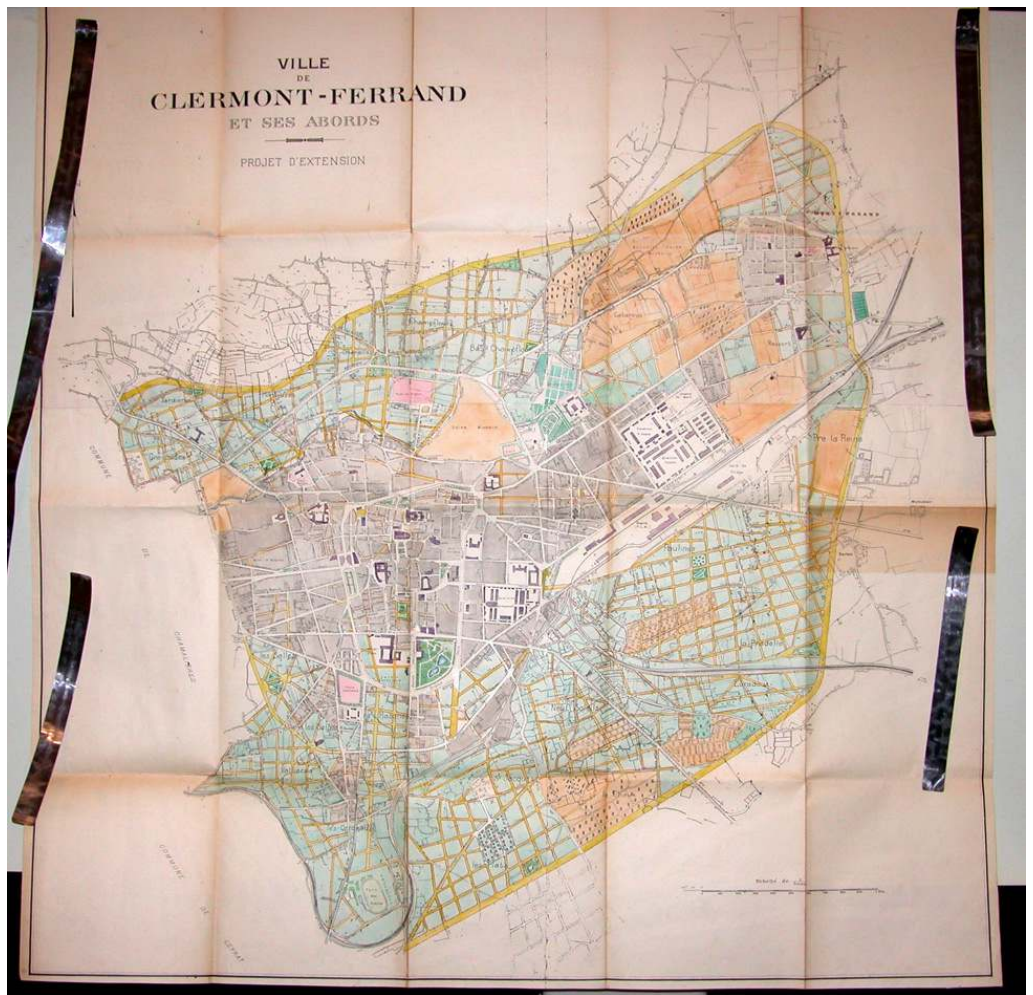

Clermont-Ferrand (Puy-de-Dôme), « Projet d'extension », Morel, ingénieur, et personnel technique municipal, 1926. Centre des archives contemporaines de Fontainebleau, versement 19810400, article 213.

Phot. Renaud, Bénédicte. (c) Région Auvergne-Rhône-Alpes, Inventaire général, ADAGP, 2010.

Il n'a rien été retenu du réseau de voirie à Aurillac, probablement car comme cela a déjà été vu, le projet de ville lié à la villégiature avait été abandonné. Dans l'industrieuse Clermont-Ferrand, le programme des damiers a reçu un début d'exécution, essentiellement dans le quartier Saint-Jacques et celui des Neuf-Soleils ${ }^{75}$, sans doute car ce système urbain, facile à tracer, a, de tout temps, répondu à une nécessité de peuplement rapide. En outre, Clermont disposait de deux modèles de villes à damier très proches, toutes deux loties à l'époque médiévale : Montferrand, et la prestigieuse Riom qui avait été sa rivale et était réputée la devancer en matière de beauté urbaine. Des voies destinées à faciliter la liaison entre villes basse et haute ont aussi été réalisées (la rue Jean-Richepin ouverte en 1936 par exemple) (fig. 10). En 1950, néanmoins, l'urbaniste Roger Puget, chargé de Clermont-Ferrand à la suite de Gaston Bardet, rejette « un grand nombre de voies prévues à cette époque [en 1926] mais a tenu compte de celles qui ont reçu un commencement d'exécution ", comme le boulevard Joseph-Girod semble-t-il (fig. 11). 


\section{Figure 10}

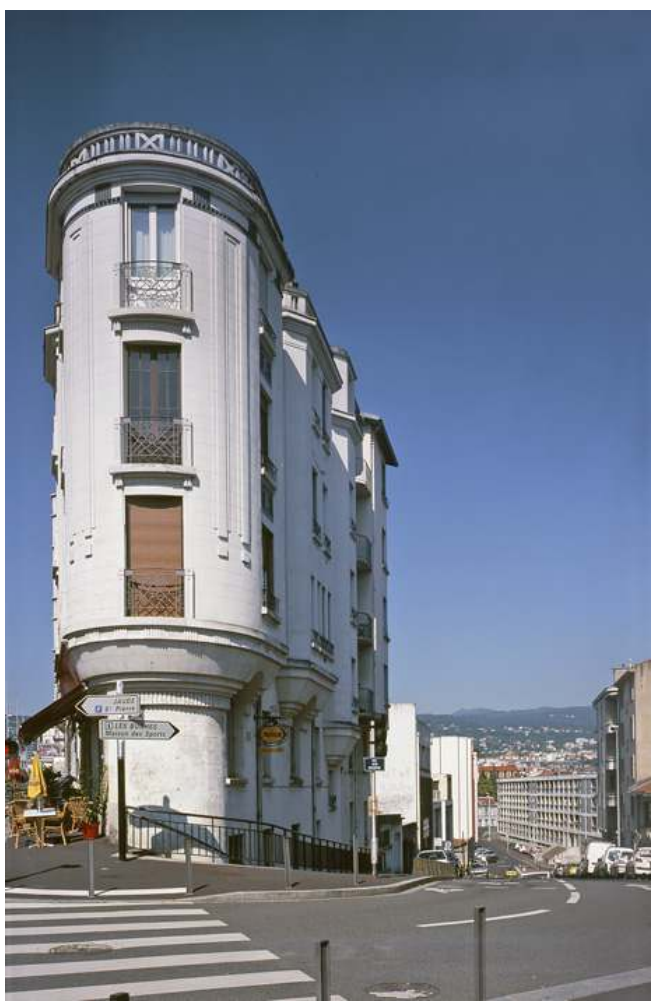

Clermont-Ferrand (Puy-de-Dôme), la rue Richepin depuis la rue Montlosier, avec à gauche, la tour d'angle d'un immeuble d'Ernest Pincot.

Phot. Périn, Jean-Michel. @ Région Auvergne-Rhône-Alpes, Inventaire général, ADAGP, 2010.

\section{Figure 11}

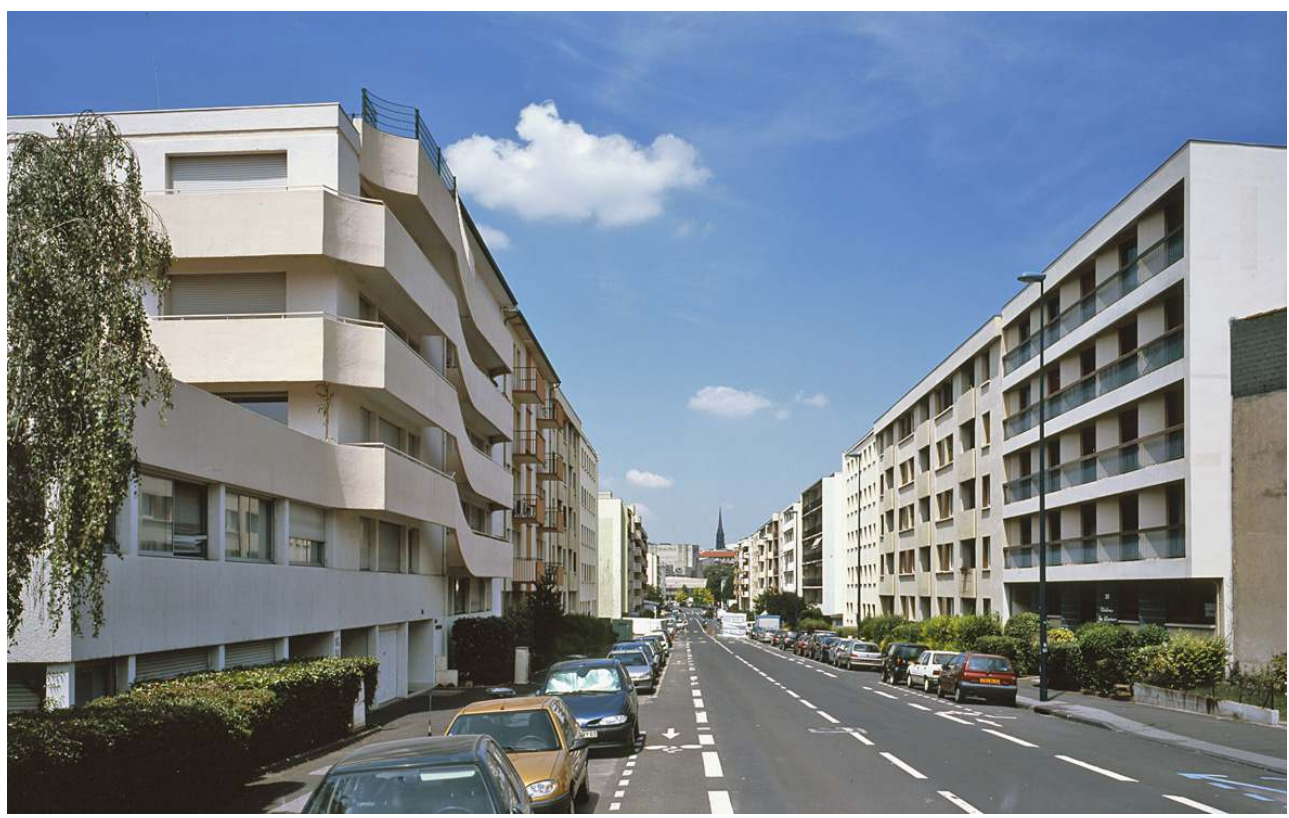

Clermont-Ferrand (Puy-de-Dôme), le boulevard Joseph-Girod.

Phot. Périn, Jean-Michel. (c) Région Auvergne-Rhône-Alpes, Inventaire général, ADAGP, 2010 
46 dans ce cas, le site très accidenté imposait un peu plus qu'ailleurs la fidélité aux courbes de niveau. À Châtel-Guyon, un petit motif en spirale correspondant à un accès à un monticule naturel formant belvédère émerge discrètement d'un plan plutôt voué à la ligne droite (bien lisible sur le plan publié de 1930).

Des damiers plus ou moins étendus, au maillage plus ou moins serré, sont proposés aussi à Chamalières, Aubière et Beaumont, mais jamais de manière aussi systématique qu'à Clermont-Ferrand. De simples « râteaux » (sorte de damier réduit), agrémentés de voies en « $Y$ », remplacent les damiers dans certains cas, ainsi à Royat et Cusset.

Pour Clermont, en accordant le décret d'utilité publique du plan, le Conseil d'État avait émis cependant plusieurs vœux, dont celui que, dans certaines zones, le «réseau des voies devrait affecter moins la forme d'un damier, et prévoir des rues convergentes, aboutissant à des places ou à des squares, de façon à donner à ces quartiers un aspect moins monotone et plus pittoresque $\aleph^{76}$. De la même façon, en 1921, quand Louis Bonnier, dans son rapport à la Commission supérieure concernant le projet de Néris, félicitait le concepteur, l'ingénieur Mercier, pour la « méthode à la fois large et prudente, artistique et pratique ", il observait encore que "les tracés de voies nouvelles pourraient être plus souples et ne pas se composer uniquement de lignes droites ou brisées. L'alignement courbe peut résulter naturellement des mouvements du sol et des courbes de niveau en donnant des formes plus agréables au paysage urbain ${ }^{77}$.

Damiers et "râteaux " peuvent être associés ainsi à des étoiles ou à des demi-étoiles à Néris, Châtel-Guyon (sur la version «1930, DDE» qui semble avoir tenu compte de l'unique réclamation concernant les dimensions de la place des Gunchères) et Cusset. Ces étoiles ou "voies convergentes» sont des figures de composition héritées de l'aménagement des forêts et parcs des XVII et XVIII siècles, très utilisées en milieu urbain au xIX siècle, notamment dans le cadre de l'haussmannisme. À Bellerive-sur-Allier, Jean Descoutures invente le néologisme approprié: les artères "s'étoilent» des places carrefours qui devront former la trame des lotissements futurs ${ }^{78}$. À Néris, une demi-étoile a été réalisée, la grande étoile de Cusset ne l'a pas été, non plus que celle de Châtel-Guyon.

\section{Les « figures de style »}

Les voies larges, droites, bordées d'arbres, avec carrefours larges, circulaires ou à pans coupés, ont constitué une "figure Cornudet ». Un carrefour mal dégagé constitue le seul obstacle à l'obtention par Bellerive-sur-Allier de sa DUP ${ }^{79}$. Cependant, si « la belle avenue de Ballainvilliers " (Clermont-Ferrand) ${ }^{80}$ (fig. 12), large, droite et arborée (tronçon du cardo maximus aménagé au XVIII ${ }^{\mathrm{e}}$ siècle), l'avenue de Royat, " voie magistrale de $10 \mathrm{~m}$ de chaussées, bordées de larges trottoirs plantés ${ }^{81}$ » (fig. 13), et le boulevard Raspail, à Paris, sont admirés comme des modèles, des précautions sont prises à Beaumont, Royat et Chamalières par les ingénieurs Vaurs, Bergoin, Férérol et Renard, lorsqu'ils déclarent que les voies trop larges « paraissent souvent froides, désertes, tristes ${ }^{82}$ ». 
Figure 12

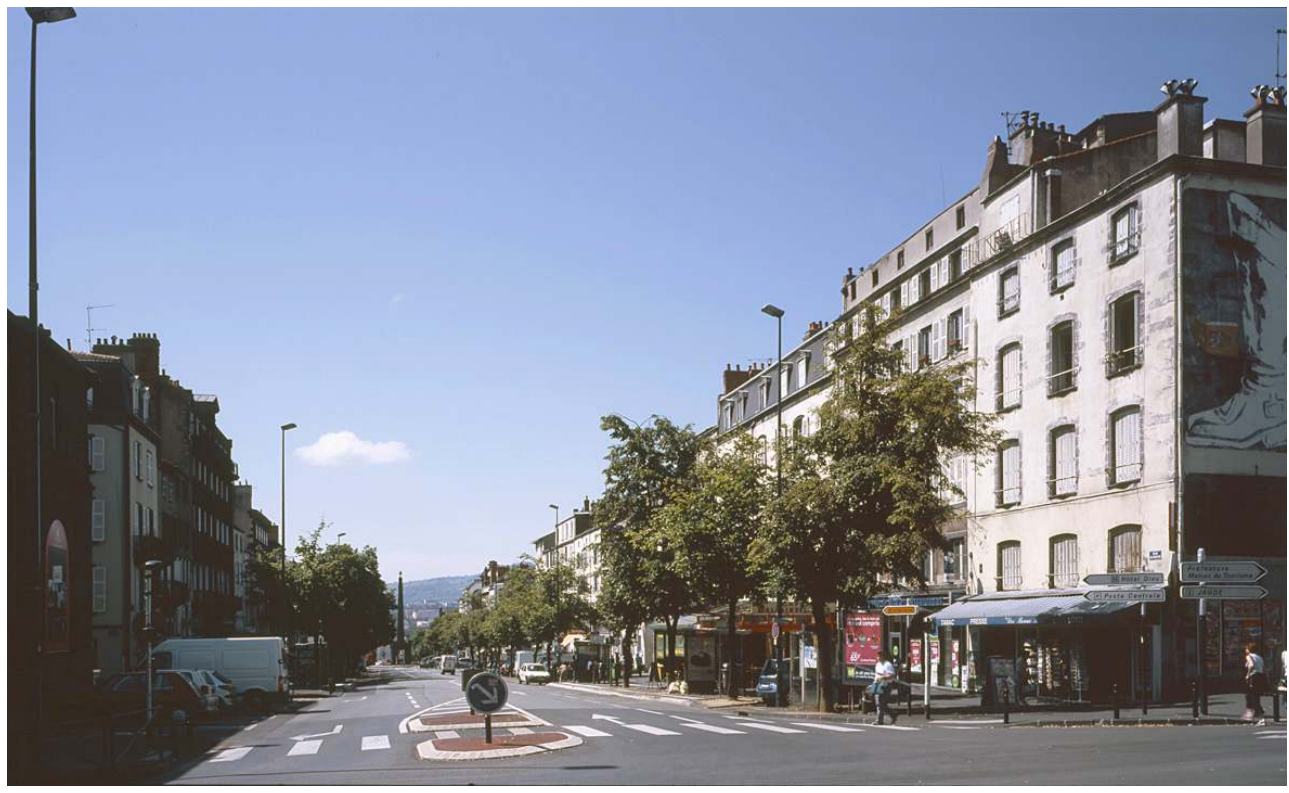

Clermont-Ferrand (Puy-de-Dôme), la rue Ballainvilliers.

Phot. Périn, Jean-Michel. (c) Région Auvergne-Rhône-Alpes, Inventaire général, ADAGP, 2010.

Figure 13

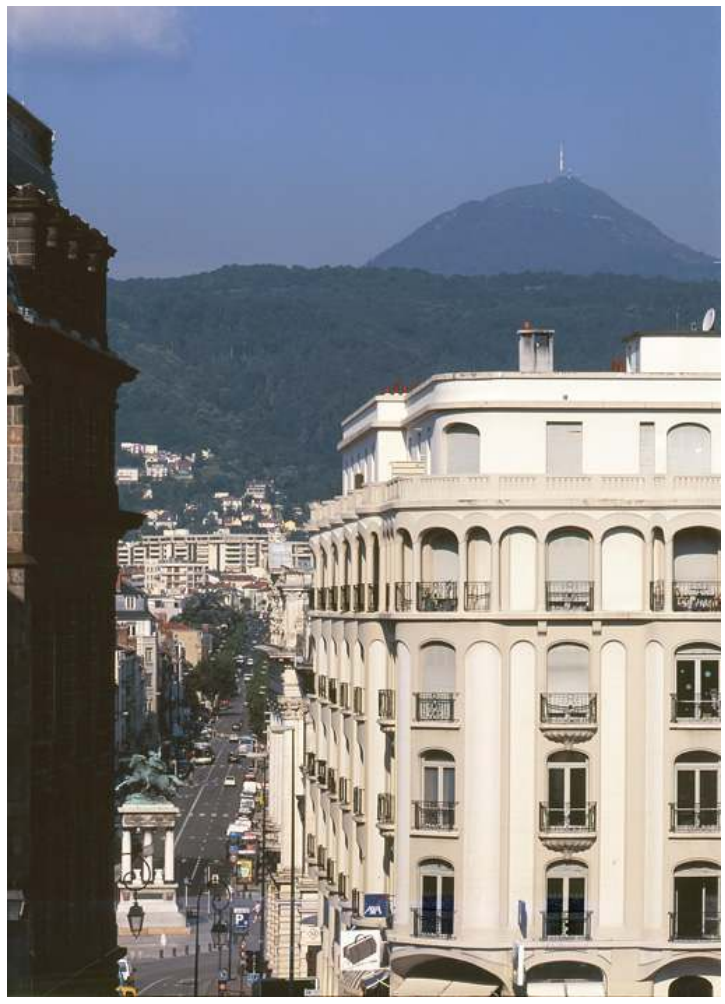

À cheval sur Clermont-Ferrand et Chamalières : la rue Blatin prolongée par l'avenue de Royat. Phot. Périn, Jean-Michel. @ Région Auvergne-Rhône-Alpes, Inventaire général, ADAGP, 2010.

51 C'est cependant d'une démesure de cet ordre que pâtit l'avenue Jean-Heitz à Royat (un point de vue verdoyant rééquilibre l'impression générale, mais seulement dans le sens de 
la descente) (fig. 14). On pourrait y trouver un écho lointain de Viollet-le-Duc lorsqu'il écrivait, dans les années 1860 : «Ainsi nos villes deviennent des déserts pour la pensée, elles ont la monotonie fatigante de la solitude sans en avoir la grandeur. À travers ces immenses échiquiers de rues, quel souvenir vous émeut? $»^{83}$.

Figure 14

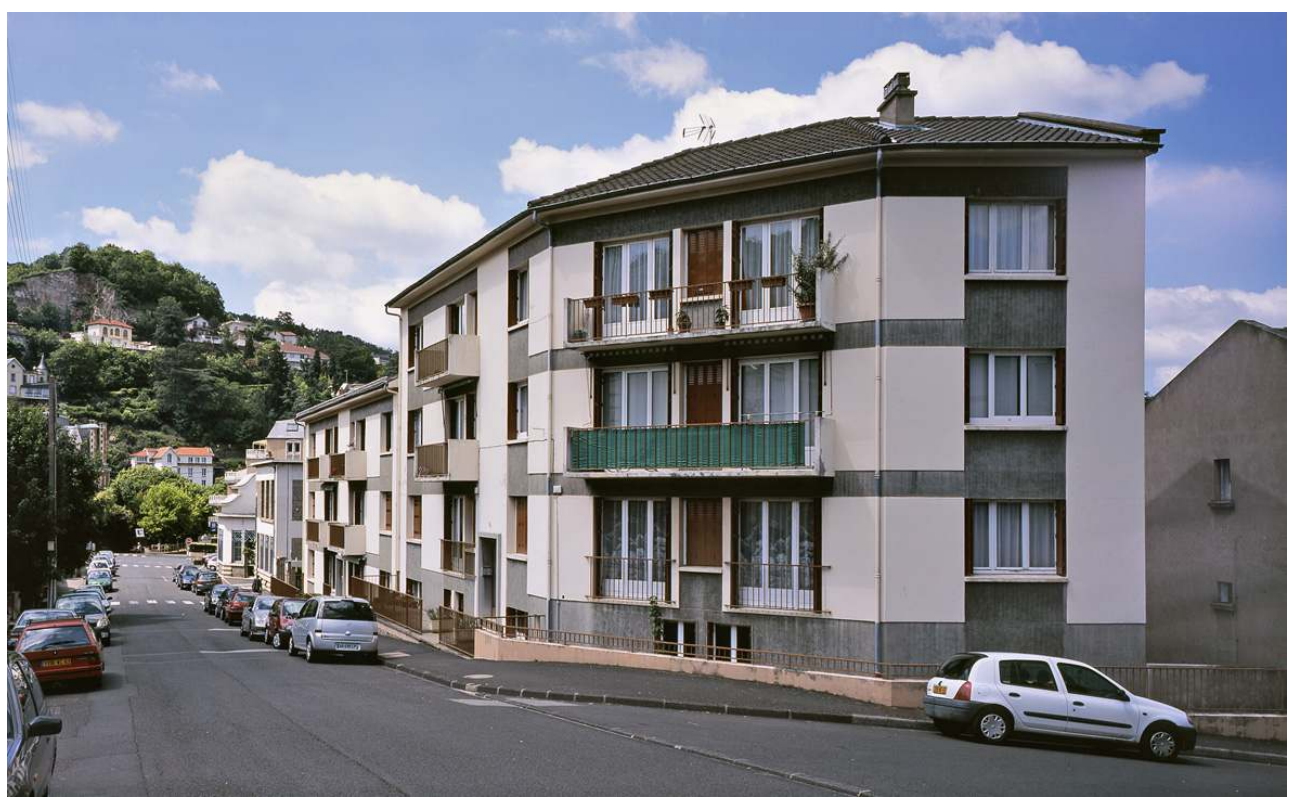

Royat (Puy-de-Dôme), l'avenue Jean-Heitz.

Phot. Périn, Jean-Michel. ( ) Région Auvergne-Rhône-Alpes, Inventaire général, ADAGP, 2010

Ajoutons ici que des facteurs inattendus doivent aussi être pris en compte : à Montluçon, la Commission supérieure de défense passive encourage la "réalisation des prolongements, redressements et élargissements de certaines voies de communication » en ce qu'elles favorisent la dispersion de la population et la diminution de la vulnérabilité de l'agglomération aux éventuelles attaques aériennes ${ }^{84}$. De l'avis du rapporteur Bérard,

les belles voies de $16 \mathrm{~m}$ [plan de Châtel-Guyon, 1929, secteur sud-ouest] dont le tracé [est soumis à la Commission supérieure] devront être profondément modifiées et mieux s'adapter au terrain dont la configuration générale d'après le tracé des courbes de niveau est délicieusement montueux et permettrait un tracé de voies souples, s'étageant en amphithéâtre au dessus de Châtelguyon et n'auraient pas la monotonie affligeante de celui qui vous est proposées.

Cette injonction a été depuis lors " entendue ", ou bien s'est-elle tout simplement trouvée mieux adaptée, puisque le plan actuel de Châtel-Guyon montre en effet à cet endroit des rues onduleuses (postérieures à un plan topographique de 1959). Le problème des rues courbes, pour René Danger, réside dans l'impossibilité d'y dresser des façades harmonieuses, il faut donc y pratiquer le retrait d'alignement ${ }^{86}$.

Charles Letrosne préconisait de «transformer toute l'agglomération de Royat en un vaste jardin » en plantant des arbres touffus le long de la plupart des voies nouvelles, de même que le long « de toutes les anciennes où l'espace le permettrait ${ }^{87}$ ». Tandis que l'ingénieurvoyer Lavilatte, pour Moulins, mettait l'accent sur un aspect conflictuel des instructions en déclarant : « les arbres ne devront avoir une hauteur de fût supérieure à $5 \mathrm{~m}$, la taille sera renouvelée tous les deux ans pour permettre aux immeubles de recevoir 
l'air et la lumière ; on rejettera les essences donnant trop d'ombrage, la plantation ne devant avoir pour objet que de meubler et orner les rues ou avenues $»^{88}$.

Largeur, bordures d'arbres et recul d'alignement sont ici les critères de la rue idéale. Dès cette époque, la rue-corridor est mise à mal (c'est-à-dire avant que la charte d'Athènes ne "l'officialise ", dans d'autres termes) : Jean Descoutures, pour le bureau Topoplan, écrit dans son programme pour Saint-Nectaire qu' « on peut difficilement admettre aujourd'hui que les maisons soient implantées au bord de la route comme on le faisait jadis. On n'aurait pas idée d'ouvrir sa porte au ras du chemin de fer » (ces images ont pour vertu de frapper les esprits) $)^{89}$, « on évitera la morne enfilade des rues sans joie [...] ». Il s'agissait pour J. Descoutures de justifier un retrait sur alignement, à l'exemple des cités-jardins, qui a pour effet d'élargir visuellement la rue, mais aussi peut-être de constituer un premier pas vers sa dislocation, la végétation des jardins de façade en particulier donnant un caractère flou au corridor dessiné (fig. 15).

\section{Figure 15}

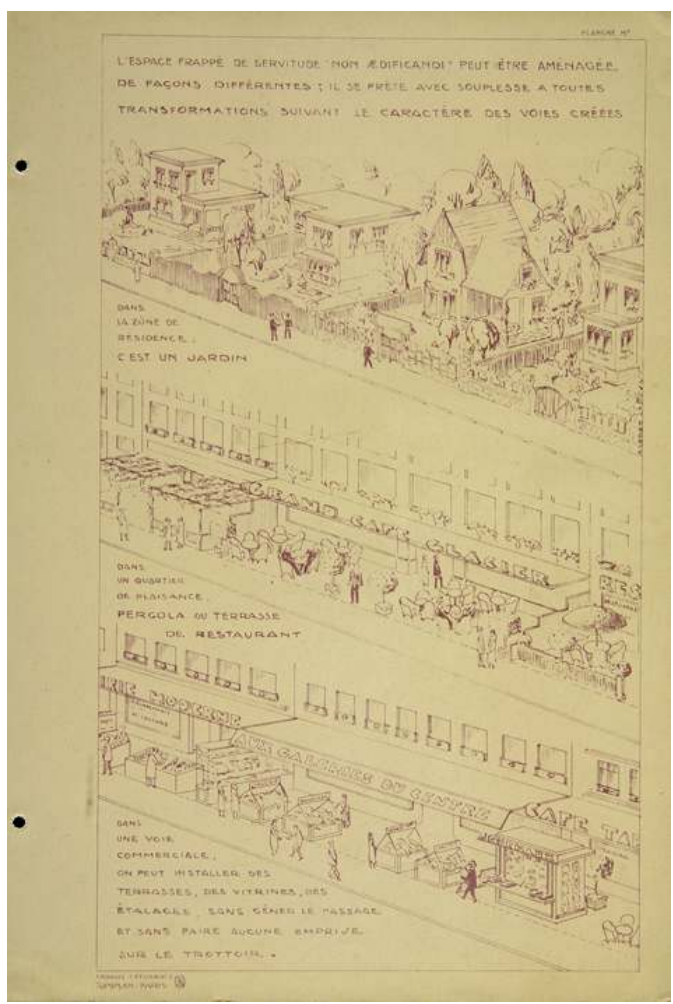

Illustration du Mémoire-programme du Plan d'aménagement de Saint-Nectaire, par Jean Descoutures, urbaniste, pour la société Topoplan, 1933. Archives départementales du Puy-de-Dôme. M 60841 ( http://archivesdepartementales.puydedome.com).

Repro. Da Costa-Vigne. (c) Archives départementales du Puy-de-Dôme, 2010.

Le square aussi, parfois qualifié de «square-prise-d'air», devient un accessoire indispensable de la rue au nom des "parents surmenés et donc affaiblis ", qui doivent pouvoir disposer d'espaces clôturés où leurs enfants pourront s'ébattre, sans avoir à se préoccuper des dangers que représente la circulation automobile ${ }^{90}$.

En matière de voirie, les boulevards de ceinture, routes et promenades panoramiques font aussi partie des "figures Cornudet». Les uns et les autres peuvent être conjugués : à Néris, par exemple, la nouvelle promenade (qui aura des vues sur le ravin de 
Cournauron), sera large de $27 \mathrm{~m}$, «ce qui permettra de disposer d'une chaussée de voitures de $8 \mathrm{~m}$, d'une allée pour piétons de $8 \mathrm{~m}$ également avec deux rangées d'arbres, d'une piste cyclable de $4 \mathrm{~m}$ avec une rangée d'arbres [...] et de deux trottoirs [...] (non réalisé). À La Bourboule aussi, il semblerait que le «chemin de ceinture dominant l'agglomération » qui constitue une "promenade idéale », suive le tracé du boulevard de ceinture. Une route panoramique est projetée à Royat (ainsi qu'à Aubière où l'on prévoit "une voie nouvelle formant corniche touristique») et des boulevards extérieurs à Montluçon, Aurillac, Cusset, Clermont-Ferrand. Dans ce dernier cas, un début de réalisation du boulevard extérieur, large de $35 \mathrm{~m}$ (actuel boulevard Louis-Loucheur), peut être mis à l'actif de la loi Cornudet (fig. 16).

Figure 16

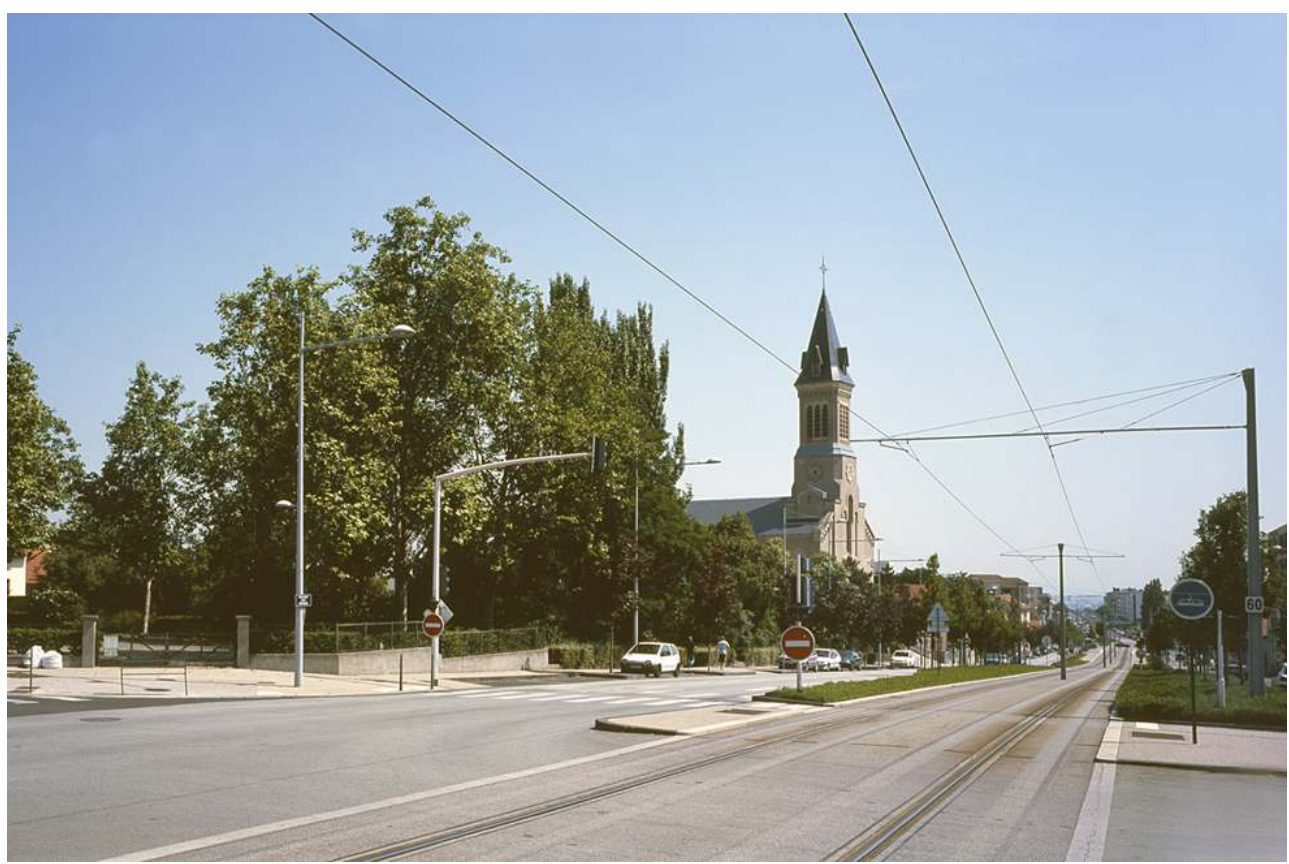

Clermont-Ferrand (Puy-de-Dôme), le boulevard Louis-Loucheur, avec le square Loucheur à gauche, ouvrant sur un pan coupé du carrefour.

Phot. Périn, Jean-Michel. ( ) Région Auvergne-Rhône-Alpes, Inventaire général, ADAGP, 2010

On remarquera à ce sujet que, d'une part, mettre en valeur les beautés naturelles était un objectif de Jean Descoutures pour Saint-Nectaire (mais le projet n'a pas été approuvée' ${ }^{11}$, et que, d'autre part, le paysage "naturel » environnant est plutôt appréhendé de manière «dominante »: c'est le point de vue privilégié, comme le belvédère ou la route de corniche, qui donne une vue d'ensemble ${ }^{92}$. Sept ans après que le PAEE de Clermont a été approuvé (en 1933), le conducteur-voyer principal de la Ville, dans le même état d'esprit vis-à-vis du paysage, propose de prendre des mesures de façon à « conserver le superbe point de vue que l'on découvre de la place de la Poterne» (petite place qui jouxte l'hôtel de ville $)^{93}$. Pourtant, on pourrait avancer que c'était à une prise en considération différente qu'invitaient les « règles de nature à guider les municipalités dans l'application de la loi » puisqu'il s'agissait de «meubler les paysages urbains par des monuments ou partie de monuments formant des fonds aux perspectives ", mais le monument naturel que constitue une montagne ne s'intègre pas dans les compositions urbaines, sinon fortuitement (pourtant, les sites auvergnats se prêteraient particulièrement bien à ce 
genre d'exercice). Édouard Joyant le suggérait aussi. Un alignement droit plaît par la clarté mais ne suffit pas à lui seul à créer une perspective satisfaisante, écrivait-il en 1927, cela dépend du décor qui le borde, et du motif qui doit le terminer "monument, arrangement d'édifices ou de plantations, paysage de montagne ou de mer». Gaston Bardet est animé de la même idée lorsqu'il propose plus tard (en 1944) de laisser vacant le « fond de Jaude » de manière à ménager une vue axiale sur les montagnes (convaincu que la façade de n'importe quel édifice élevé sur le côté sud de la place pâtirait d'un mauvais éclairage) ${ }^{94}$. Une manière de composer la ville avec les monuments naturels environnants, pourtant indirectement suggérée, qui ne semble pas avoir eu de prise. Les regards n'y sont pas non plus entraînés, sauf quand l'organisation tient du spectaculaire (le puy de Dôme dans l'axe de la rue des Gras, à Clermont, par exemple). Mais qui lit un axe de composition entre le palais de justice d'Aurillac et le puy Courny (fig. 17)?

\section{Figure 17}

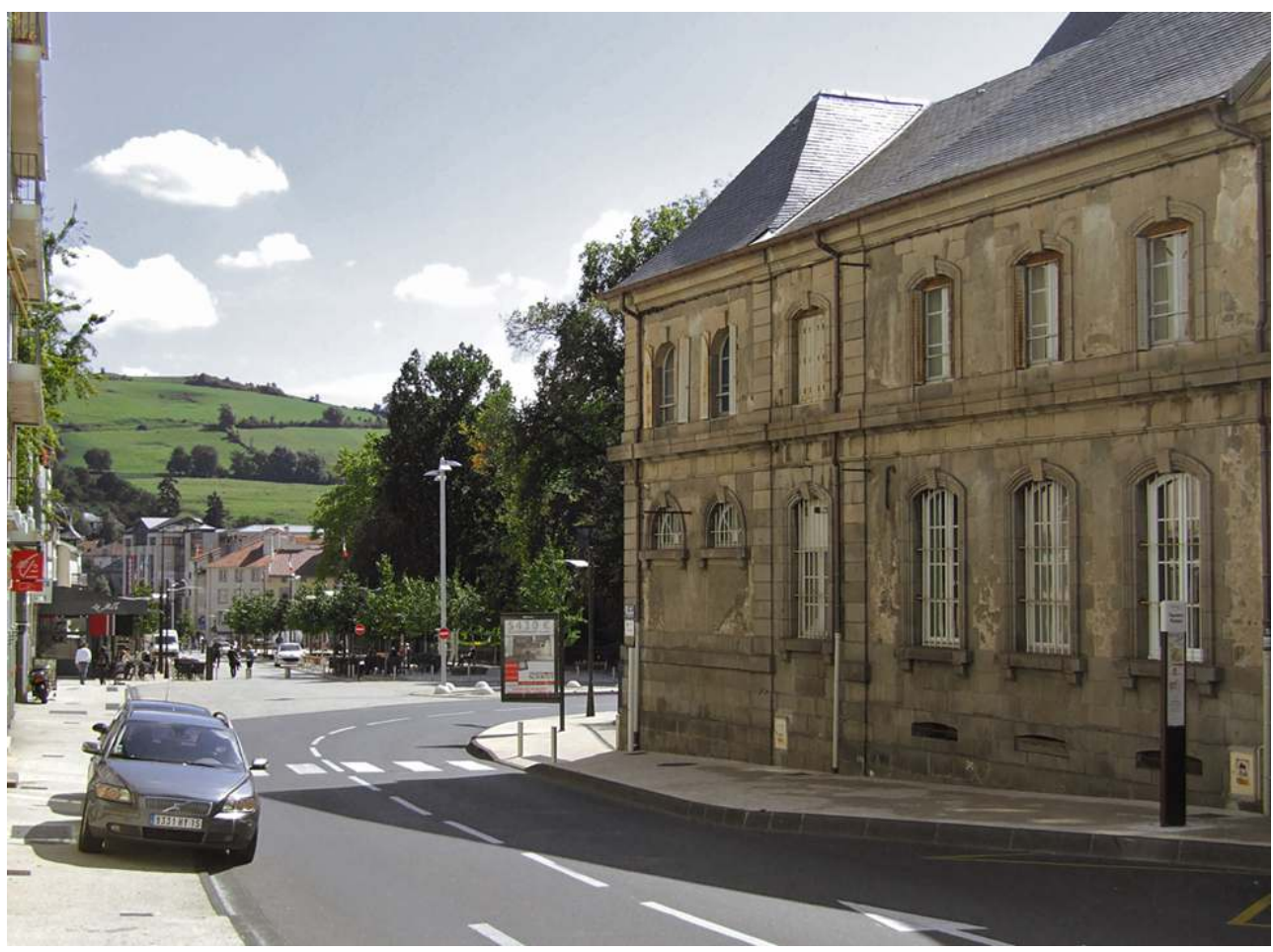

Aurillac (Cantal), la photographie peine à témoigner de certains effets du paysage urbain : par exemple, l'axe de composition que le passant, s'il y est sensibilisé, peut établir entre le puy Courny et la façade principale du palais de justice.

Phot. Périn, Jean-Michel. @ Région Auvergne-Rhône-Alpes, Inventaire général, ADAGP, 2010.

Entre l'obélisque du boulevard Lafayette de Clermont-Ferrand et le puy de Dôme (fig. 18)

? Nous sommes plus habitués à percevoir des échappées, voire des dégagements larges ; dans la ZPPAUP ${ }^{95}$ d'Aurillac le puy Courny est au moins considéré comme un «cône de vue». 
Figure 18

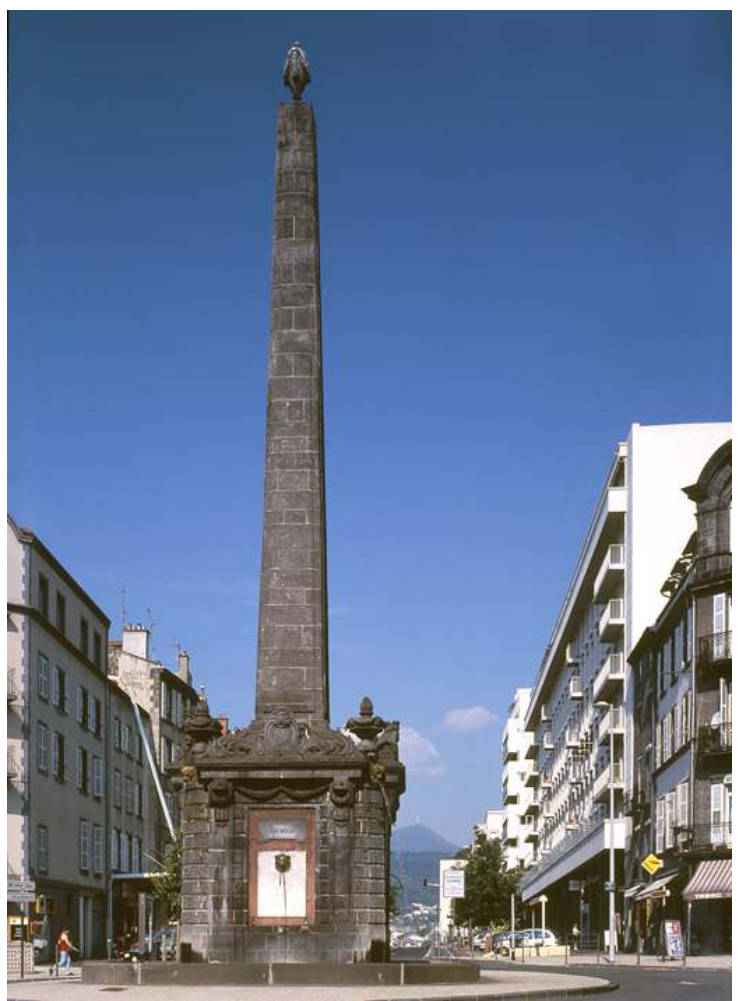

Clermont-Ferrand (Puy-de-Dôme), axe de composition reliant le puy de Dôme à l'obélisque élevé en 1801 en mémoire du général Desaix. Cet axe peut sembler fortuit sauf qu'un dessin réalisé en 1821 par Étienne-Jean Delécluze permet de lire ce dialogue entre les deux « pyramides » de manière frappante.

Phot. Périn, Jean-Michel. @ Région Auvergne-Rhône-Alpes, Inventaire général, ADAGP, 2010

Et en effet, faire entrer la nature en ville, préserver un cadre de vie lié au site s'affiche depuis l'élaboration des Plans d'occupation des sols à Montluçon, au Puy, à Aurillac, et à Clermont-Ferrand, sous le poids du lobby « vert » d'après Nora Semmoud ${ }^{96}$.

Notons au passage qu'en 1950 le maire de Clermont demande au préfet l'inconstructibilité du versant est du puy de Dôme (le versant visible depuis Clermont)... pour protéger des captages éventuels d'eaux de sources ${ }^{97}$. De même, le puy Courny à Aurillac est déclaré zone agricole sur le PAEE de 1922, le préservant des constructions. Ces deux règlementations ont ainsi très indirectement permis l'avènement de deux phénomènes urbains remarquables.

Toutes ces figures de style, prises isolément, reflètent surtout leur époque.

Dès 1912, un conseiller municipal de Moulins « déposait le vœu » que « désormais, toute maison qui se construira dans Moulins [à un angle de rue] ne puisse plus être construite qu'avec un pan coupé ». Le vœu ne prend la forme d'une "obligation municipale » (disposition ratifiée par le préfet) qu'en 1920 avec, par ailleurs, une restriction intéressante à analyser. En 1912, en effet, les arguments portaient sur trois points : en premier lieu venait, il faut le noter, que «les piétons seront moins exposés aux rencontres se produisant entre deux personnes au coin d'une rue, rencontres souvent compliquées de chassés-croisés plutôt ridicules et désagréables", puis venait la suppression des "chocs autrement dangereux » entre conducteurs, et enfin "ce serait pour Moulins un embellissement du meilleur effet». Huit ans plus tard, seuls les 
carrefours présentant un danger pour les automobiles sont concernés : ainsi, ni confort du parcours du piéton, ni embellissement urbain ne sont plus pris en compte.

Certaines villes qui présentent une ou deux de ces figures de style peuvent faire penser à des villes ayant commencé à appliquer la loi Cornudet comme, par exemple, Riom-èsMontagnes dont le plan montre bien au nord-ouest un secteur fortement structuré de larges voies se coupant à angle droit en formant des carrefours à larges pans coupés (la rue du Lieutenant-Basset en est l'axe principal). Un raccord maladroit avec la ville ancienne en forme d'étranglement peut laisser supposer un échec du plan mais la Ville, qui avait certes demandé son assujettissement à la loi, n'avait pas mené à bien le projet et s'était apparemment inspirée de préceptes en vogue pour les exécuter ponctuellement par ses propres moyens et sans passer par l'avis des différentes commissions ni $a$ fortiori avoir obtenu de déclaration d'utilité publique. Le maire de Riom-ès-Montagnes justifiait les travaux de voirie engagés en ces termes : trop de fautes ont déjà été commises qui compromettent à jamais la symétrie, l'aspect et l'esthétique de notre ville et de nos rues.

Chacun construit à sa fantaisie sans se préoccuper de ses voisins, on a saboté et gaspillé de très beaux terrains en y implantant des constructions orientées en tous sens sans aucun souci d'alignement, on a même construit dans le prolongement pourtant connu, de rues en construction, qui se trouvent ainsi barrées par des obstacles vilains et ridicules $[. . .]^{98}$.

À Riom-ès-Montagnes comme ailleurs, il fallait se prémunir aussi contre le lotisseur dont il était dit qu'il «considère comme un terrain perdu toute surface de voie publique ou d'espace libre : il ne donne aux rues que le minimum de développement et de largeur [...] et réduit l'aménagement des voies à un empierrement sommaire " ${ }^{99}$. D'une façon générale, les lotisseurs étaient tenus de suivre les tracés de la voirie prévue par le PAEE, dès lors qu'il avait été dressé. Les commissions départementales étaient d'ailleurs chargées d'examiner tous les projets de lotissements, qu'il s'agisse d'initiative privée ou de société100. Par exemple, entre le 30 mars 1925 et le 19 décembre 1926, trente-huit demandes d'autorisation de lotir avaient été examinées dans le Puy-de-Dôme (concernant principalement Clermont-Ferrand); en 1937, il y en a eu quarante-huit. La conjugaison " plan Cornudet » et lotissement d'HBM (habitations à bon marché) a été fréquente : à l'extrémité de l'avenue Aristide-Briand à Chamalières (fig. 19) par exemple, ou dans le quartier Saint-Jacques de Clermont. Dans ce deuxième cas où une plus grande liberté semble avoir été donnée aux habitants, il est par ailleurs frappant de constater que les pans coupés des carrefours du quartier sont particulièrement pauvres, contrairement à une pratique «traditionnelle » qui voulait que l'on profite de cette figure urbaine pour exposer son décor (seule, dans le quartier, une façade d'école publique s'inscrit encore dans la tradition), comme si l'on n'avait plus aucune conscience de participer au " théâtre de la rue », ou bien comme si cette attitude était typiquement urbaine et qu'il n'y avait plus de raison de s'y « soumettre » dans une zone que l'on ne ressent plus comme telle. 


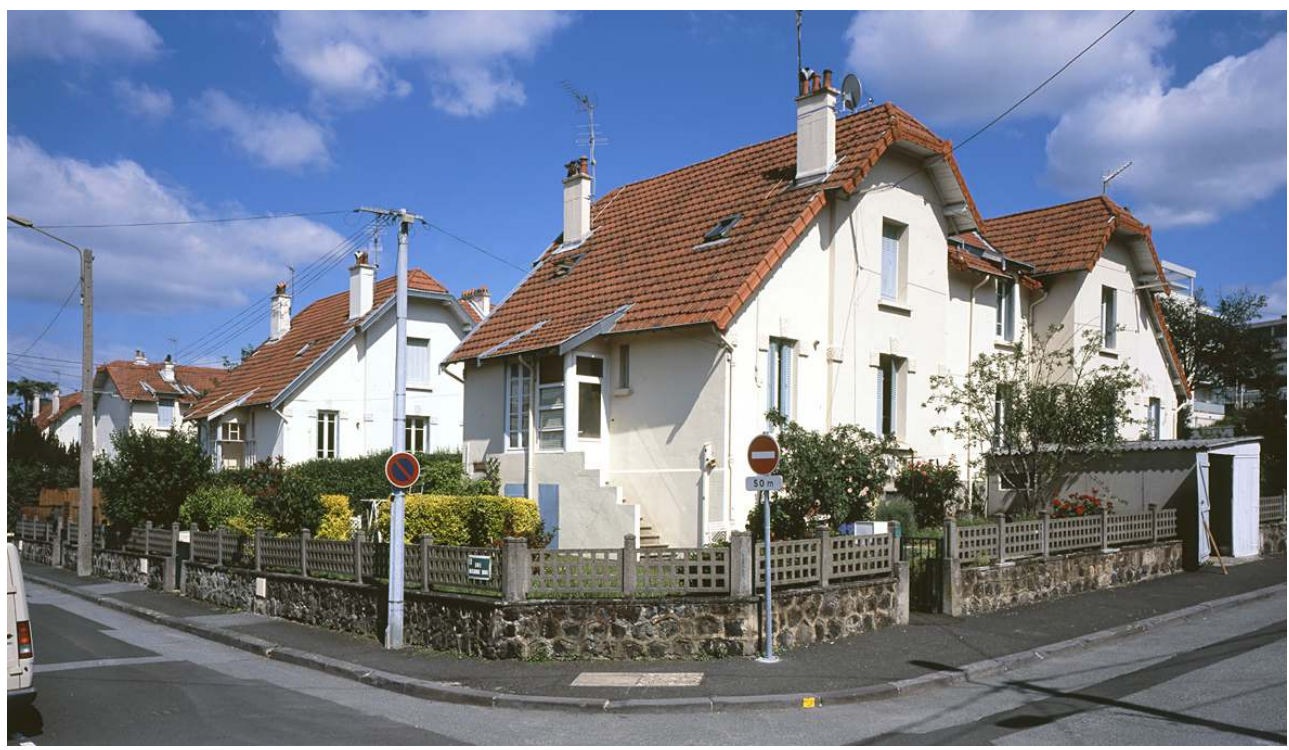

Chamalières (Puy-de-Dôme), quartier des habitations à bon marché prévu sur le plan et réalisé. Phot. Périn, Jean-Michel. @ Région Auvergne-Rhône-Alpes, Inventaire général, ADAGP, 2010.

C'est ainsi que certains lotissements organisés au cordeau font penser à des «figures Cornudet ». L'amorce d'un damier dans un secteur de La Bourboule apparaît sur un plan de 1889, qu'il est prévu d'étendre sur le PAEE de 1932. La station n'obtient pas la DUP mais le lotissement sera tout de même réalisé.

Les figures de style « Cornudet » étaient dans l'air du temps : un rapport demandé à Vichy en conseil municipal le 24 septembre 1912 le montre encore et de manière radicale, confirmant finalement l'idée selon laquelle les textes de lois n'émergent que lorsqu'une majorité de la société est prête à l'appliquer ${ }^{101}$. Il est rédigé par un conseiller municipal dénommé Richardet Aîné, imprimé le 9 décembre 1918 à Vichy et est intitulé «Plan d'alignement et plan d'aménagement, d'embellissement et d'extension, rapport au conseil municipal $»^{102}$. Sans s'appesantir sur le fait que le rapporteur semble mal renseigné puisqu'il prétend que "Vichy ne peut même justifier, chose incroyable, d'un plan d'alignement complet et régulièrement approuvé », on peut lire que « des coupes hardies et inexorables » s'imposent dans le vieux Vichy, que de « larges et belles voies » doivent y être ouvertes, tout en respectant "tout ce qui offre un caractère d'histoire locale». L'extension de la ville « devra être prévue aussi vaste que possible » car, insiste-t-il, « nul ne peut prévoir l'apogée » de la station. Des espaces libres devront être prévus « surtout dans les quartiers populeux et ouvriers ", « les perspectives et points de vue doivent être ménagés avec art et méthode ». Il faudra se préoccuper de «l'aspect décoratif » des rues, "séparer les différentes activités spécialisées d'une ville (industrie, commerce, administration, habitations bourgeoises, habitations ouvrières et à bon marché, [...] », etc. Mais surtout, l'auteur fait remonter l'origine de ces idées à l'exposition " pour les plans d'extension des villes » qui s'était tenue à Londres en 1900 et où la France s'était « sous ce rapport, laissée complètement dépasser ». Ainsi les modèles se trouvent-ils à l'étranger : l'Allemagne est citée pour ses "riches périphéries", l'Amérique pour sa capacité à "préserver les beautés naturelles qui entourent les villes » et son système de zonage, l'Angleterre pour savoir ménager des perspectives «sur de riants coteaux », l'Autriche 
pour « le choix raisonné de l'emplacement des édifices publics », la Suède pour exiger des rues nouvellement percées une largeur minimale de 13 mètres et viser plutôt les 28 mètres. Enfin, Richardet citait les pays dans lesquels des textes de loi facilitaient la mise en œuvre de telles prescriptions (d'après lui, la Hollande disposait déjà d'un texte de loi sur les plans d'extension depuis 1902; en Italie, une loi d'expropriation pour utilité publique existait depuis 1865 , etc.).

Rares, en revanche, ont été les villes qui se sont préoccupées explicitement de leurs avenues d'entrée, à l'exception de Durtol (elles devaient présenter une "unité de caractère ») mais le projet global a été refusé puis la procédure abandonnée ${ }^{103}$, et de Montluçon, où les entrées du faubourg principal devaient être marquées par deux bâtiments identiques et imposants (projet global non abouti) ${ }^{104}$. Pour Vichy, c'est la Commission supérieure qui s'en préoccupe, en signalant que d'après le plan proposé, le nouvel établissement des postes s'interposait entre l'entrée de ville que constituent la gare et les thermes : cette disposition devait être revue ${ }^{105}$.

Par ailleurs, on pourra noter qu'en Auvergne, en matière d'espaces libres, sauf dans le cas de la station thermale de Royat, les squares, les jardins privés, d'un côté, et les terrains de sport, de l'autre, sont privilégiés par rapport aux grands parcs et jardins (voir à Commentry où, d'après le rapporteur en Commission supérieure, il manquait un parc dans le projet... réalisé depuis : le " parc de la mine », sans que la ville ait fait aboutir son PAEE proprement dit). Et cela à l'image de Clermont-Ferrand dont le PAEE ne prévoit « aucun grand parc public et dans sa forme définitive dix squares, dont certains sont peu réalistes comme celui du quartier St Éloy [...]. » écrit M. Antonio, qui conclut :

En fait, pour les édiles clermontois, les espaces verts semblent peu utiles à l'exception de ceux qui sont voués, soit à une étude (jardin botanique), soit à «distinguer» une frange influente de l'électorat, comme le jardin Lecoq, soit encore à une source de moralisation du prolétariat (jardins ouvriers). Cette mentalité peut aussi s'expliquer par la brusque mutation de Clermont. L'esprit rural demeure, bien que le cadre urbain soit bouleversé par l'irruption massive de l'industrie. Aussi ne voit-on pas l'intérêt de créer des espaces verts, d'autant plus que le merveilleux site de la ville rappelle constamment la proximité de la nature ${ }^{106}$.

Concernant les espaces arborés, à Chamalières, la parade avait été trouvée : présence de nombreux jardins privés, caractère de la commune à demi-rurale, etc., comme à Durtol où il suffisait de constituer en réserves les bois environnants. Le grand jardin public, ou encore mieux, la grande place publique ne serait donc pas une figure classique des PAEE en Auvergne. À Aubière et Chamalières, deux grandes places étaient prévues mais le projet global d'Aubière n'a pas abouti tandis que Chamalières a obtenu sa DUP mais les places n'ont pas été réalisées. À Aubière, où l'hôtel de ville devait trôner sur une place, le choix a été fait entre-temps d'agrandir la mairie dans un langage architectural moderne, jouant la représentation et la monumentalité sur ce contraste, plutôt que sur la mise en scène d'un large dégagement ; l'église, elle, a été " désencombrée ", à coups de résorption d'îlots insalubres, mais dans un registre qui n'est pas celui de la grande place régulière.

De quels délais les villes disposaient-elles pour mettre en œuvre leur projet? Dans le texte de loi modifié de 1924 sont évoquées les périodes de quinze et de trente ans. Les effets de la loi doivent en effet être mesurés au moins à cette aune : l'ingénieur en chef des Ponts et Chaussées pour le Puy-de-Dôme (Hennequin) concluait son rapport concernant Châtel-Guyon en ces termes :

Voici les grandes lignes d'un projet d'aménagement et d'extension que le conseil municipal prévoit. Certaines parties seront réalisées durant le mandat actuel ; mais 
nombreuses sont celles qui ne pourront s'exécuter que dans un avenir encore lointain et au fur et à mesure du développement du pays, qui, nous l'espérons, ira sans cesse croissant ${ }^{107}$. entretenir avec les villes limitrophes), mais aussi, paradoxalement (?), en termes de zone. Le zonage commence alors à se pratiquer en France. Il ne s'agit pas que d'un " volontarisme dû à des professionnels ivres de pouvoir ", il faut aussi séparer l'habitat de l'industrie ${ }^{109}$, protéger les sites naturels et les intérêts du tourisme, etc. ${ }^{110}$. La Commission supérieure rappelle à l'ordre les concepteurs qui ne raisonnent qu'en « paquets » (Royat) ou qui ne tracent pas sur leur plan de manière rigoureuse les limites des zones présentées dans les textes (Beaumont, Durtol, Royat, Saint-Nectaire). Les règlements y sont différents, notamment en matière de hauteur d'immeubles. Et on envisage ces règlements «transitoires et tendres » pour les parties déjà construites et " plus rigoureux pour les parties vierges » (Chamalières, 1930). la « vieille ville » (Le Puy), « la ville anciennement bâtie » (Durtol), le «quartier ancien central » (Chamalières), qu'on oppose à la zone d'extension (ou le quartier neuf), à la zone de maisons individuelles ou résidentielle, à la zone industrielle, agricole ou rurale, ou « de culture maraîchère " (Aubière), et éventuellement à la zone "des jeux et sports" (Bellerive-sur-Allier). Il n'y a que La Bourboule pour se déclarer jeune ville.

Il s'agit donc, à cette époque, de zonage à mi-chemin entre le fonctionnel et le morphologique. On note aussi un sous-zonage par catégorie sociale : à Aurillac, où l'on place les cités ouvrières en fond de vallée et les villas sur les hauteurs; à ClermontFerrand, où l'on remet «à plus tard la réglementation de l'aspect extérieur des immeubles dans les quartiers où le développement des constructions de luxe pourrait le nécessiter ${ }^{111}$ ». C'est d'ailleurs sur la question des servitudes esthétiques que les Clermontois étaient le plus mal à l'aise : en témoignent des demandes adressées à d'autres villes (Grenoble, Reims, Strasbourg, Lille, Marseille ${ }^{112}$ ). Dans les archives municipales est conservé un document émanant apparemment d'un juriste intitulé «Servitudes 
d'esthétique imposées aux constructeurs» qui débute par la phrase: «En principe l'autorité municipale ne peut imposer aux propriétaires des servitudes de construction dans un but d'esthétique ». Suivent, pour le prouver, des arguments référencés, datés entre 1844 et 1920, qui laissent perplexe.

Ces zones sont les premières d'un genre dont Jean-Baptiste Minnaert écrit que «les historiens, les urbanistes et les décideurs mesurent depuis longtemps le simplisme et les effets pervers, dans le diagnostic comme dans l'action ${ }^{113}$. Pour l'heure, il s'agit d'en profiter néanmoins pour examiner comment chaque ville s'arrange ou prévoit de s'arranger officiellement de sa "vieille ville", afin de saisir comment le patrimoine architectural et urbain s'intègre dans la démarche d'aménagement de l'entre-deuxguerres.

\section{De la table rase prévue à Montluçon à la conservation intégrale de Beaumont}

Tous ces noyaux anciens auvergnats sont caractérisés principalement par des «rues étroites et tortueuses ». À Clermont, un décompte précis donne corps à cette observation des chargés de projet et des maires: dans la ville historique, Marcel Antonio a recensé 340 rues, ruelles, impasses dont la largeur moyenne tourne autour des 6-7 m, dont plus de 150 sont en dessous de ce chiffre. L'expression - zone à « rues étroites et tortueuses »revient dans chaque dossier, avec cette variante de noyaux construits "au petit bonheur ». Ce premier constat est assorti d'un second: la difficulté qu'il y a à les moderniser, surtout lorsque, comme à Beaumont, le vieux bourg est situé « sur un versant très déclive ». Pour la Société française des architectes-urbanistes, les destructions de la Première Guerre étaient quasiment considérées comme une chance pour les villes (de se reconstruire plus rationnellement); en Auvergne, Pierre Estienne observait en 1960 qu'aucune guerre n'était venue modifier, depuis longtemps, l'aspect des villes (fig. 20). 


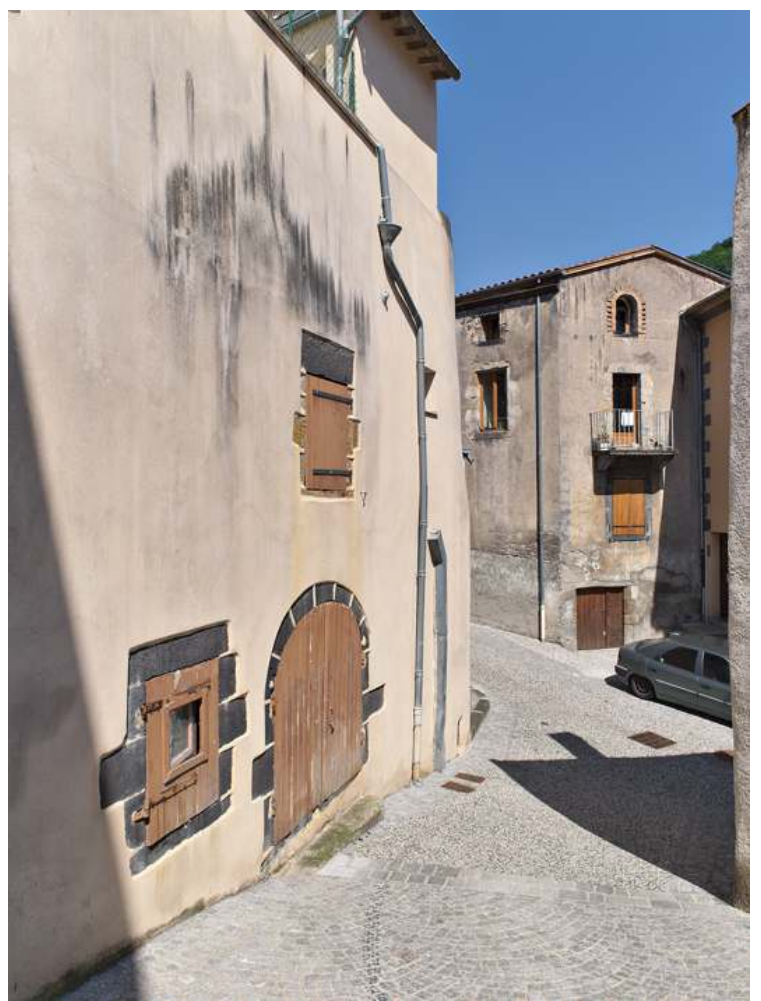

Royat (Puy-de-Dôme), rue du Château : rue tortueuse qui devait disparaître au profit d'une percée rectiligne si le PAEE avait été entièrement exécuté.

Phot. Périn, Jean-Michel. (C) Région Auvergne-Rhône-Alpes, Inventaire général, ADAGP, 2010.

Il y a là tiraillement, que les instances locales et nationales tentent de résoudre, entre la volonté d'aménager une ville où l'air, la lumière et les automobiles circuleraient mieux, où les habitants seraient moins nombreux (" plus éparpillés »), et l'ambition de préserver un tissu pittoresque, voire un " aspect moyenâgeux » (Royat), un « caractère régional », une " physionomie locale » (Aubière) ${ }^{114}$, mais surtout - l'argument est plus intéressant de ne pas porter atteinte à une « ville agréable à habiter » (Beaumont, Chamalières).

Notons au passage que la notion de pittoresque pouvait s'appliquer aussi bien au paysage urbain qu'au paysage naturel environnant, sans oublier le «pittoresque des voies convergentes ", plus difficile à entendre. Il s'agit d'une valeur positive qui oriente la planification, contrairement à ce qui guidait auparavant Haussmann, puis, à la même époque, Le Corbusier (la première version de son " plan Voisin ", pour Paris, est de 1925, la charte d'Athènes qui entérine le mépris pour « le chemin des ânes » date de 1943). Dans les dossiers auvergnats, le pittoresque est rarement "programmé ", c'est-à-dire que même le régionaliste Charles Letrosne, auteur de Murs et toits pour les pays de chez nous (1923), préconise la conservation d'un "pittoresque » hérité plus qu'il n'encourage à la construction dans un style régional. À Montluçon, L. Bonnier craignait le « faux vieux " quand l'architecte proposait «une architecture qui s'adapterait au caractère d'ensemble ». Il n'y a que dans le programme de Durtol où il est demandé explicitement aux architectes «d'apporter harmonie et pittoresque ", où « la Ville se réserve le droit d'imposer un même type d'édifice correspondant au style de construction régional, afin de constituer un ensemble pittoresque », mais on sait que Durtol n'ira pas beaucoup plus 
loin dans la procédure. Le terme de pittoresque est utilisé aussi parfois au sein de la Commission des monuments historiques, jusqu'en 1938 au moins, quand il s'agit d'évoquer les abords des édifices. L'adjectif « pittoresque » disparait progressivement à la fin de la période, de même que l'expression "rues étroites et tortueuses", pour être remplacée par exemple par « la beauté d'un réseau plastiquement ressentie ${ }^{115}$ » : il s'agit néanmoins du même patrimoine urbain.

81 La table rase est envisagée dans quelques cas et la Commission supérieure freine ces ardeurs-là : à Durtol (pour laquelle le projet « apparaît catastrophique pour l'ancienne agglomération ») et à Montluçon (où, dans un premier temps, la démolition totale de la vieille ville, hormis le château, est programmée). À Bourbon-l'Archambault, il était prévu de démolir un lot de maisons dont la mairie faisait partie, de même qu'une tour de l'ancienne basse-cour du château: Charles Letrosne, pour la Commission supérieure, demande de "ne démolir qu'avec beaucoup de prudence » les maisons, car «beaucoup d'entre elles ont des silhouettes intéressantes ", et pour la tour, il est d'avis qu'elle « contribue à donner au quartier où elle est placée un caractère régional intéressant » (il s'agit de l'actuelle tour emblématique baptisée «qui-qu'en-grogne » sur les documents touristiques).

82 Ailleurs, il s'agit de démolir "quelques pâtés de maisons ». Cela a été fait par endroits à Royat, à Clermont (quartier Saint-Éloy), à Riom (quartier des tanneries). Si tous les îlots déclarés insalubres sur le plan d'Aubière avaient été démolis, il ne resterait plus beaucoup de la ville ancienne et de ces intéressants espaces de circulation intermédiaires. Mais le projet a eu une durée de vie très limitée puisqu'il n'a pas été approuvé.

Une autre solution pour décongestionner les noyaux anciens consiste à organiser des percées : peu d'entre elles ont été réalisées, les simples élargissements de rues ayant même été difficiles à obtenir. À Cusset, les rues du centre devaient être presque systématiquement élargies et une percée devait sectionner un îlot d'après le PAEE (approuvé) : aujourd'hui on observe que le secteur concerné par la percée a été préservé (il fait la joie des touristes) mais le reste du centre a été presque totalement démoli (les grandes barres construites à la place ont fait notamment la joie des populations qui auparavant ne disposaient pas de salle de bain). La rue des Forgerons à Aurillac, pour laquelle un ambitieux projet d'élargissement et d'alignement était programmé en 1926, a conservé son gabarit antérieur. À Clermont-Ferrand, la rue Philippe-Marcombes, petite rue sur laquelle donne, étonnamment, la façade principale de l'hôtel de ville, devait déjà être élargie à l'avant de l'édifice municipal de façon à le mettre en valeur, sur une proposition de l'architecte Ledru en 1859; le PAEE de 1926 reprend à son compte cette proposition (là aussi, les plans s'enchaînent sur des propositions semblables) : la rue a résisté (fig. 21). Comme s'il était des "évidences urbaines» auxquelles les villes résisteraient. 
Figure 21

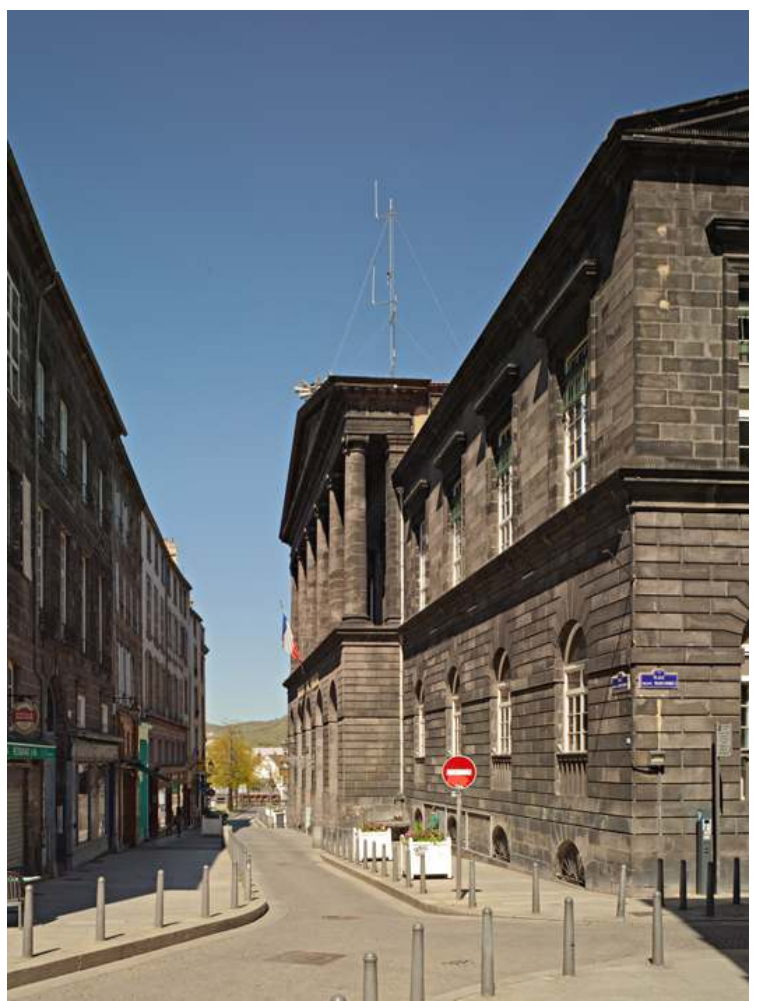

Clermont-Ferrand (Puy-de-Dôme), l'étroite rue Philippe-Marcombes, avec l'hôtel de ville, à droite. Phot. Périn, Jean-Michel. @ Région Auvergne-Rhône-Alpes, Inventaire général, ADAGP, 2010

Au Puy, la société savante des Amis du vieux Puy préconise des "squares-prises d'air » plutôt que des élargissements de voies ou des percées, et cela en prenant modèle sur quelques petites places existantes dans la vieille ville : une autre façon de reproduire un « comportement urbain » local.

\section{Les monuments historiques, entre admiration et circulation}

La politique de dégagement des édifices est l'objet de vifs conflits. Dans les cas où les édifices ont acquis le statut de "monument historique », la justification est d'autant plus utilisée, et cela joue alors comme un excès d'admiration, sinon, il s'agit de pouvoir mieux circuler (c'est le cas pour le dégagement de la cathédrale de Clermont-Ferrand en tous les cas). La protection des abords n'apparaît en effet qu'avec la loi du 25 février 1943 et n'est affinée qu'en 1962 (critère de la covisibilité, périmètre des $500 \mathrm{~m}$ ). Tout au long du XIX ${ }^{\mathrm{e}}$ siècle, ce traitement réservé aux monuments historiques et édifices publics avait eu du succès : la Sainte-Chapelle de Riom, par exemple, était « démasquée » en 1857, le parvis de la cathédrale Notre-Dame de Paris était dégagé dans les années 1860-1870, la préfecture du Cantal, à Aurillac l'était en $1880 . .$. Au début du xxe siècle, ce sont des théoriciens comme Giovannoni à nouveau qui, à la suite de Camillo Sitte et d'autres, postulent la solidarité entre les monuments d'art et d'histoire et le contexte bâti. Françoise Hamon a observé par ailleurs que la rubrique «Les barbares » de la revue L'Illustration, qui faisait état des destructions opérées par l'ennemi entre 1914 et 1918, avait suscité une sensibilité 
renouvelée au bâti ancien. Les Amis du vieux Puy écrivent en 1922, au sujet de la façade de la cathédrale :

une énorme masse très régulière qui domine la cohue irrégulière des vieilles maisons, celles-ci n'en laissant apercevoir d'aucun endroit l'ensemble mais seulement quelques parties - c'est l'irrégularité et l'exiguïté de ces maisons, par elles-mêmes sans intérêt, qui, par contraste font la grandeur imposante de la façade 116.

Les débats entre les différents acteurs auxquels l'application de la loi Cornudet donne lieu portent ainsi la trace de cette nouvelle sensibilité. En fait, rappelons-le, dès l'instruction générale de 1920, il était stipulé qu'il fallait se prémunir du "désencadrement » des chefs-d'œuvre de l'architecture nationale. Le cas de Clermont aussi témoigne des intérêts divergents: il est vrai que la «Maison de Pascal» située au pied de la façade de la cathédrale avait été démolie en 1923, trois ans avant que le PAEE de la ville ne soit approuvé, mais le projet de 1925 ajoute le dégagement de son chevet ${ }^{117}$. La section des Beaux-Arts du Conseil d'État fait valoir que ce dégagement est susceptible de faire disparaître la maison du chapitre, dont l'intérêt est assez important pour la faire échapper à l'alignement. Le Conseil d'État n'obtient pas gain de cause et le chevet est dégagé (avec pour conséquence la mise à nu de murs aveugles, récemment peints de trompe-l'œil) ${ }^{118}$ (fig. 22).

\section{Figure 22}

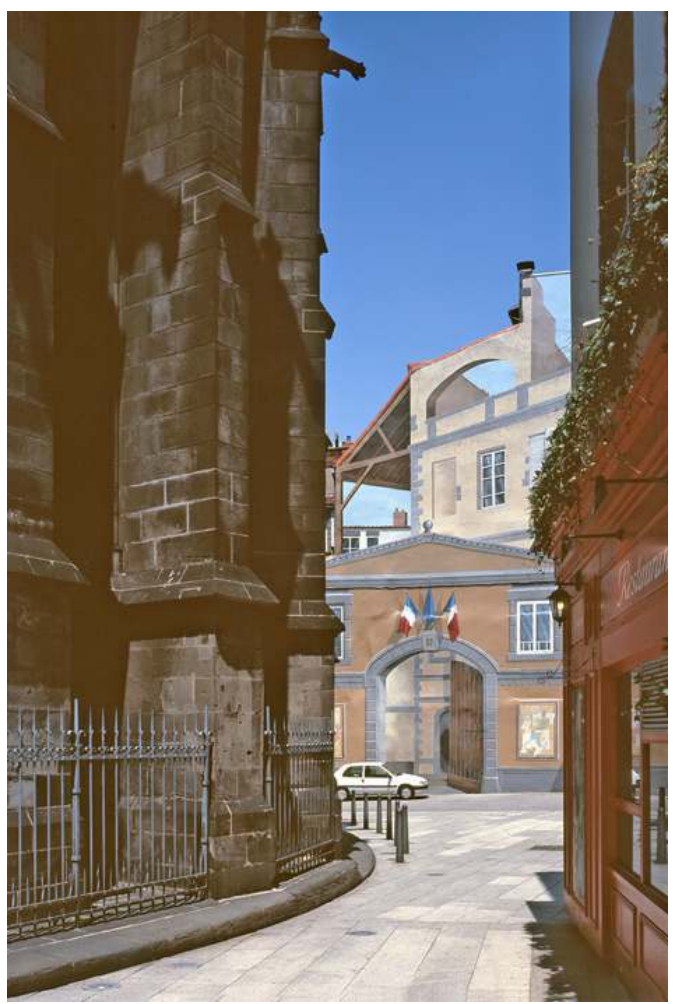

Clermont-Ferrand (Puy-de-Dôme), dégagement au chevet de la cathédrale.

Phot. Périn, Jean-Michel. @ Région Auvergne-Rhône-Alpes, Inventaire général, ADAGP, 2010

Actuellement, et cela depuis les années 1960 (l'avènement des PSMV ${ }^{119}$ puis des ZPPAUP ${ }^{120}$ en sont des indicateurs), les édifices sont plus difficilement désolidarisés du tableau qu'ils composent avec leur environnement immédiat mais le débat n'est pas éteint. 
88 de 1930, ce qui donne alors un nouveau relief à la dynamique de la protection du patrimoine urbain ${ }^{121}$. Pour Viviane Claude, le «jeu particulier, plus compliqué qu'il n'y parait, et avivé durant cette période, entre une administration de la conservation et celle de l'aménagement » commence à " prendre forme et force ». C'est grâce à cette nouvelle instance que la maison des architectes de Clermont (actuel musée du Ranquet) n'est pas démolie, comme la Ville en avait le projet en 1933, dans le but d'élargir la « Petite rue Saint-Pierre ", à l'occasion du réaménagement de la place du Marché-Saint-Pierre (fig. 23).

Figure 23

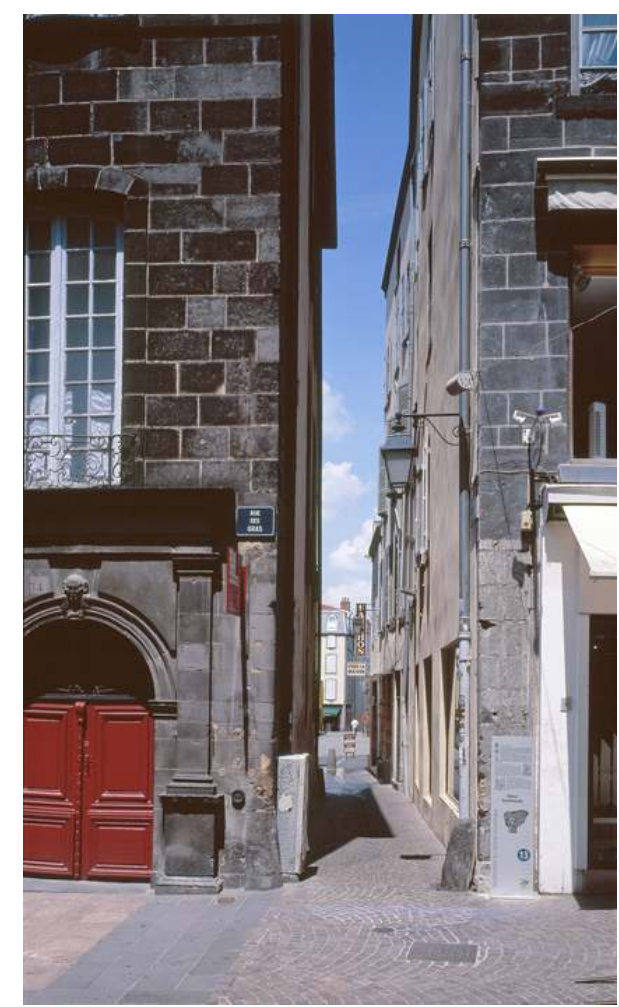

Clermont-Ferrand (Puy-de-Dôme), la petite rue Saint-Pierre.

Phot. Périn, Jean-Michel. @ Région Auvergne-Rhône-Alpes, Inventaire général, ADAGP, 2010

89 À l'autre extrémité de cette place, quelques maisons ont été néanmoins mises à bas, comme cela était noté sur le PAEE, avec la même conséquence qu'au chevet de la cathédrale, soit un front d'élévations secondaires aveugles, repercées par la suite pour certaines d'entre elles.

90 Cependant, avant même que la Commission des monuments historiques ne se mêle directement de l'épineux problème (équilibre entre conservation et renouvellement urbain), le concepteur du PAEE de Néris-les-Bains, l'ingénieur Mercier, était félicité pour avoir expliqué notamment dans son programme :

Il existe bien, dans ce Néris ancien, des rues étroites, aux parcours tortueux et dont le tracé respecte peu les exigences de la voirie moderne. Nous n'avons pas trop osé y toucher, parce que cela ne nous paraissait ni indispensable, ni même réalisable. Les rues en question sont en effet bordées de petites maisons bourbonnaises à simple rez-de-chaussée, comportant jardin derrière et souvent, jardinet par devant. Les maisons à un étage y sont déjà rares et les maisons à deux étages y constituent 
l'extrême exception. La densité de population y est donc relativement faible et, en tous cas, parfaitement compatible avec les nécessités de l'hygiène. Ensuite la circulation qui s'y exerce est purement locale [... $]^{122}$.

91 Globalement, les projets destructeurs étaient les moins bien appréciés dès avant 1930 (pour exemples, les projets de la ville de Montluçon, 1923-1926, de la station de Bourbonl'Archambault, 1929).

92 C'est ainsi, pour une part, qu'entre difficulté à aménager et attachement à « une ville agréable à habiter ", les centres anciens ont généralement été conservés, et que les géographes et urbanistes actuels sont autorisés à constater que les villes auvergnates continuent de se caractériser par des centres à « réseaux désordonnés de rues ».

\section{Conclusion. Pour l'avenir : " examiner les écarts entre les dispositions d'origine des plans et ce qu'il en est advenu dans la réalité »}

Confirmant l'analyse de Christian Jamot sur la représentativité des villes d'Auvergne à l'échelle nationale, nous notons qu'à tout moment nous avons pu vérifier les considérations générales énoncées par Viviane Claude ${ }^{123}$. Dans les détails cependant les réactions ne procèdent pas du même mouvement.

Les plans produits restent aussi des indices pour nous qui cherchons à retrouver comment les villes se sont rêvées à un moment donné: immense échiquier pour Clermont, immense parc paysager (à la façon du Vésinet) pour Aurillac, par exemple. Attachées à leur noyau ancien désordonné « agréable à habiter » (Beaumont), prêtes à la table rase (Montluçon, Durtol)... Il y a encore à faire ressortir les municipalités convaincues des bienfaits de la planification, les plus promptes à réagir, et les autres. À la première place figurerait Aubière, qui se proposait dès 1920 de monter son dossier mais qui a dû attendre 1927 pour y être autorisée dans le cadre de la loi (sinon, précisait le préfet, elle le faisait «à ses risques et périls »). Puis viendraient Néris-les-Bains (1921), Aurillac et Le Puy-en-Velay (1922), Clermont-Ferrand (1925). Encore faudrait-il distinguer, dans ce premier groupe, celles qui sont intéressées par la création d'une voirie capable de structurer l'extension mais que l'aménagement de l'existant inspire moins. Vichy occupe une place à part puisque le conseil municipal devançait le texte de loi en 1912 en annonçant un rapport sur la question, paru en 1918. Au Puy-en-Velay également, l'architecte de la Ville A. Proy désigne le maire comme "précurseur de la loi Cornudet » puisqu'il lui avait été demandé de dresser dès 1907 un "plan d'alignement et d'embellissement $~^{124}$. Comme à Châtel-Guyon, où l'on note une approbation d'un plan général de travaux d'embellissement et d'assainissement de la station thermale au 8 mars 1917125. Il faudrait alors enquêter sur la personnalité des maires actifs à cette période car il se pourrait qu'ils montrent, comme à Riom-ès-Montagnes, un goût tout particulier pour la prévision urbaine conjugué à un pouvoir d'entraînement fort. Mais la nouvelle législation arrivait peut-être simplement au bon moment pour ces agglomérations. Aurillac se détache aussi de ce groupe en affirmant par son projet sa volonté de changer de fonction urbaine (de ville essentiellement administrative, elle se projetait en lieu de villégiature). Parmi les moins enclines à répondre, à se reconnaître dans un esprit planificateur (Moulins, Saint-Yorre, Le Chambon-sur-Lignon, Ceyrat, Issoire, Riom, Thiers), on notera le cas de Riom, qui avait déjà prétexté l'existence d'une ville régulière 
et entourée de boulevards pour ne pas se soumettre à la loi de 1807 qui obligeait les villes de plus de 2000 habitants à se doter d'un plan d'alignement, comme si l'opération d'aménagement importante qu'elle avait connue à l'époque médiévale - ne concernant que le centre - la dispensait de revenir sur la question.

L'examen de ces dossiers, malgré leur disparité, révèle des gisements d'informations lorsqu'on cherche à mettre au jour des articulations entre des représentations urbaines en vogue et des réalités locales.

En effet, quand Charles Letrosne recommandait pour Royat de diminuer la hauteur règlementaire des immeubles, surtout «dans le Royat-thermal », de manière à « ne pas faire ville », il s'était heurté aux ingénieurs, sensibles à la continuité du paysage urbain de l'agglomération, qui rétorquaient qu'il "ne saurait être appliqué de nouvelles dispositions pour les bâtiments à construire sans nuire gravement à l'esthétique de ces voies $»^{126}$. Ce refus d'un «changement de règles du jeu » en cours de route (qu'on peut comprendre, car l'accepter pour les hauteurs d'immeubles, c'est en fait comme susciter des ruptures d'alignement, l'un comme l'autre à l'origine de la découverte souvent désagréable de murs mitoyens pauvrement traités) se trouve confronté à la représentation théorique des lieux de villégiature que s'est construite un membre de la Commission supérieure.

En outre, ces échanges appartiennent à un passé relativement proche, ce qui amène très directement des éléments de compréhension des territoires urbains actuels, y compris parmi les plus ordinaires qu'on ne songe pas à interroger mais qui ont à parler d'une époque et d'intentions (par exemple, l'axe de la rue du Lieutenant-Basset à Riom-èsMontagnes, le quartier Saint-Jacques à Clermont, la place Gouttebel de Cusset...). La consultation des projets et plans à peine anciens permet d'attirer l'attention sur les choix opérés et d'en constater ou non la pertinence, autrement dit de nourrir un regard critique sur les transformations des villes et sur l'environnement quotidien des citadins.

Par ailleurs, ces débats montrent comment des questions que notre époque croit neuves possèdent un arrière-plan historique et sont réactivables à l'envi, même si la vivacité de certains constats peut inquiéter (l'extension chaotique des villes, à laquelle on pensait porter remède dès cette époque-là). Les objectifs urbains peuvent avoir été renversés entre-temps : la densification prônée actuellement, même si elle n'est pas unanimement adoptée, a succédé à l'objectif de dédensification de ces années-là («l'éparpillement des populations ", "moins d'habitants, plus d'arbres", dans un but prophylactique, sans compter les préconisations de la défense passive).

Les effets immédiats de la loi ont certes été minimes (son principal défaut était pour certains l'absence de caractère contraignant) mais il est difficile de mesurer son impact dans les esprits. La "solution moderne » du zonage a décidément très bien fonctionné même si elle n'en était ici qu'à ses prémices. En revanche, la rue-corridor "à l'ancienne " a très bien résisté dans les centres en Auvergne, surtout lorsqu'elle est tortueuse et étroite. Elle fait maintenant partie du patrimoine urbain auvergnat.

En outre, par le biais de la consultation des plans existants dans les mairies ou de la mémoire conservée par certains acteurs, de projets émis à ce moment-là, des réalisations peuvent se prévaloir indirectement d'une origine « Cornudet ». Il reste une interrogation par exemple au sujet d'une partie réalisée du PAEE de Cusset : le damier centré autour de la place Claudius-Gouttebel est prévue dans le plan de Jean Descoutures de 1935, il n'apparaît pas sur le plan de l'état des lieux dressé par Gaston Bardet en 1943, ni sur le 
plan d'aménagement de 1947 mais en revanche le même Bardet l'avait repris sur le plan d'aménagement du Grand Vichy de 1943 - qui intègre les communes voisines de la station thermale, dont fait partie Cusset - et aujourd'hui, sans qu'on ait encore cherché à dater précisément sa réalisation, il existe (fig. 24). Par quel processus ce type de rémanence passe-t-il ? Faut-il y voir le caractère spécialement réfléchi et adapté au contexte des plans produits dans le cadre de cette loi, comme le suggère Vincent Flauraud pour le cas d'Aurillac? Observons néanmoins, d'une part, que les textes officiels, par exemple les arrêtés préfectoraux, sont souvent précédés d'attendus qui pourraient inciter à se plonger dans les documents produits précédemment. Un arrêté préfectoral concernant le règlement de voirie de Montluçon datant de 1960 fait référence à l'édit royal de 1607 jusqu'à une ordonnance de 1958 , en passant par un alinéa de la loi de 1807 relatif à l'alignement des rues, etc. D'autre part, il semblerait que l'existence d'un document graphique confère un pouvoir démesuré à toute proposition, même longtemps après sa production $^{127}$.

Figure 24

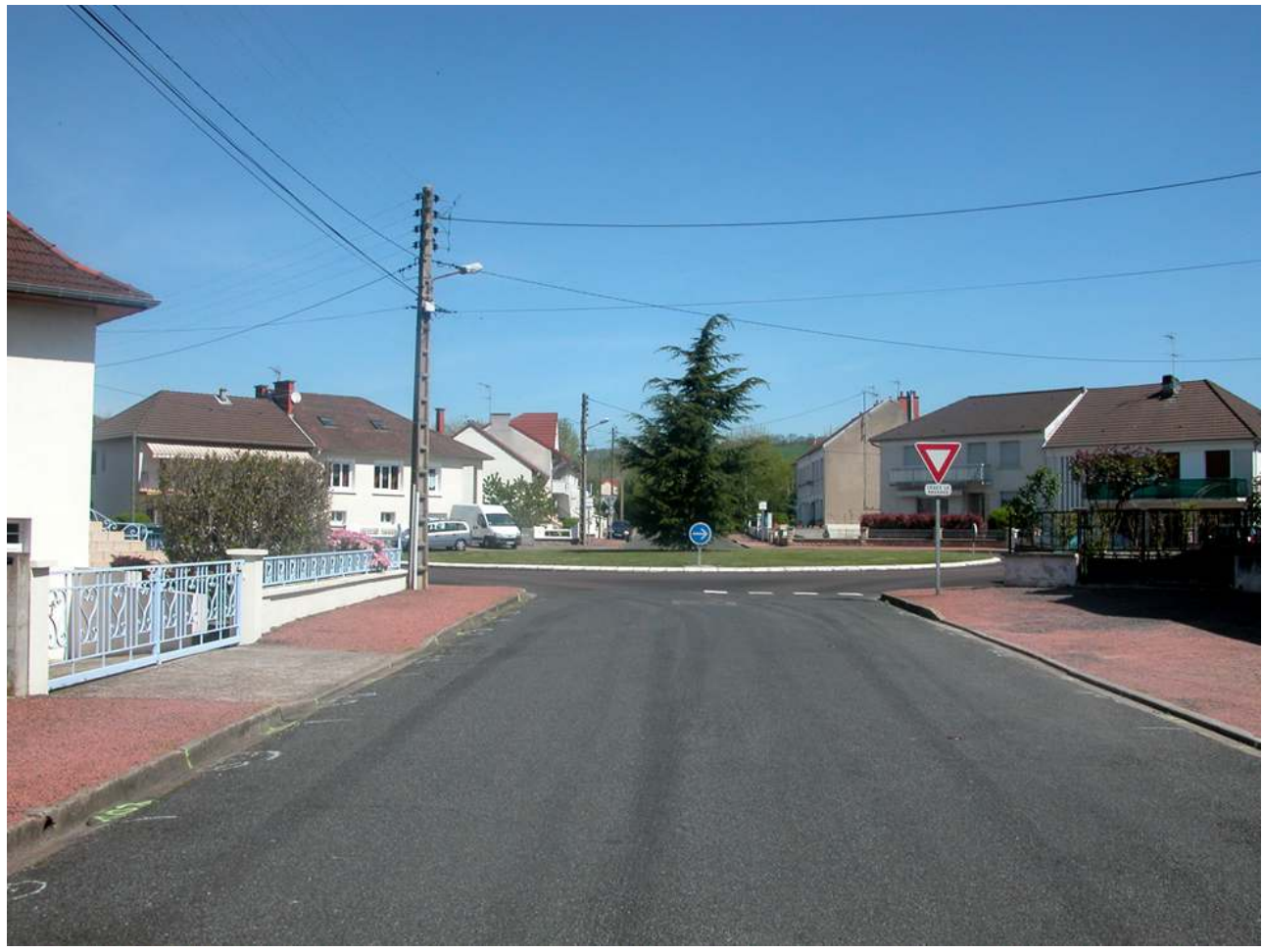

Cusset (Allier), la place Claudius-Gouttebel. Place-carrefour qui, dans ce quartier résidentiel, peut sembler démesurée.

Phot. Renaud, Bénédicte, 2010. (C) Région Auvergne-Rhône-Alpes, Inventaire général.

Il serait intéressant, pour chacune des villes, de mieux saisir les articulations entre les PAEE et les projets les ayant précédés, et entre les PAEE et les projets qu'elles se sont donnés par la suite (en commençant par les plans d'aménagement issus de la révision des premiers, puis en continuant par les plans d'urbanisme directeur d'après la Seconde Guerre) et de les suivre jusqu'à aujourd'hui. Bien sûr, Gaston Bardet proposait en 1946 à la municipalité clermontoise de rejeter complètement le principe du PAEE de 1925 en ce qu'il «étendait la ville concentriquement avec un luxe de voies extrêmement dispendieux » alors que lui préconisait « un développement en étoile, avec des coins de 
verdure pénétrant aussi profondément que possible», puis "en bordure du plateau central, de conserver un anneau de verdure $[. . .]^{128} »$. Cependant, très clairement, le maire de Clermont-Ferrand concluait une séance du conseil municipal du 2 décembre 1952 consacrée au nouveau plan d'aménagement de la ville en ces termes : «Bien entendu, les stipulations des anciens plans (1859 et 1926) resteront en vigueur lorsqu'elles ne seront pas expressément mises en cause par les dispositions du nouveau projet ${ }^{129}$.

En fait, l'exercice même de planification, envers lequel les acteurs locaux avaient montré souvent quelque réticence, a été assez tôt l'objet de critiques de la part de certains professionnels. Un tel exercice, pour perdre sa rigidité, devait absolument recevoir un prolongement d'après Gaston Bardet (1939), qui proposait une interprétation dynamique de « l'esprit » du plan primitif par un urbaniste-conseil affecté à chaque ville. Le procédé de la planification à longue échéance, même s'il a connu un essoufflement à partir des années 1960 puis un renouveau sous d'autres formes, demeure critiqué et l'on aimerait savoir en quoi consiste cette nouvelle urbanisation, qui n'aurait pas "pour point de départ une planification abstraite » mais pourrait se nourrir « de la vie et de l'énergie présentes dans la cité », qu'annonçait récemment l'exposition « Uneternal city.fr. Urbanism beyond Rome » (Paris, pavillon de l'Arsenal, 18 février-27 mars 2010).

Quoi qu'il en soit, il pourrait être utile de tenter d'écrire une histoire régressive des paysages urbains par le prisme des effets des différentes lois d'urbanisme, ou, dit dans les mêmes termes que proposait en 1969 la Société centrale pour l'équipement du territoire au sujet des grands ensembles, de

continuer à examiner les écarts entre les dispositions d'origine des plans et ce qu'il en est advenu dans la réalité, pour rechercher d'éventuelles causes ou corrélations. À cet égard, la constitution d'une banque d'informations sur les résultats des opérations, bien que tournée vers le passé, serait riche d'enseignements pour les projets à venir ${ }^{130}$.

\section{Voir Annexe 2 : Le projet de Jean Descoutures pour Bellerive-sur-Allier}

\section{Voir Annexe 3 : Tableau récapitulatif}

Voir Annexe 4 : Carte des villes concernées par la loi

\section{Liste des abréviations}

$\mathrm{AD}$ : archives départementales

$\mathrm{AM}$ : archives municipales

CAC Fontainebleau: Centre des archives contemporaines (Archives nationales)

Ingénieur TPE : ingénieur des travaux publics de l'État

PAEE : Plan d'aménagement, d'extension et d'embellissement

$\mathrm{rdcm}$ : registre des délibérations communales

s.d. : sans date 


\section{NOTES}

1. - Je remercie Jean-Baptiste Minnaert d'avoir bien voulu relire la première version de cet article et de m'avoir fait part de ses observations et encouragements, ainsi que Philippe Vergain, Renaud Benoit-Cattin, Georges Coste et Bernard Toulier. Cet article, à quelques détails près, a déjà été mis en ligne sur le site du service de l'Inventaire d'Auvergne[-Rhône-Alpes], à l'adresse: www.auvergne-inventaire.fr [consulté le 11/08/2016].

2. - JAMOT, Christian. «Villes et morphologie urbaine en Auvergne ». Dans CERAMAC. L'Auvergne urbaine. Mythes et réalités de la ville auvergnate. Clermont-Ferrand: Presses universitaires BlaisePascal (coll. CERAMAC, $\mathrm{n}^{\circ}$ 12), 2002, p. 186-199.

3. - Pour toute question d'ordre général concernant cette loi, nous renvoyons à CLAUDE, Viviane. « Les projets d'aménagement, d'extension et d'embellissement des villes (1919-1940). Sources et questions ». Paris : Ministère de l'Équipement, du Logement, des Transports et de la Mer, rapport, novembre 1990. Les textes de loi et la circulaire y sont retranscrits en annexe.

4. - AM Montluçon, série $1 \mathrm{~T} 1 / 2$. Extrait de délibération du conseil municipal du 2 décembre 1921. Observons d'une part que paradoxalement, le député Cornudet n'est pas cité, d'autre part que la ville de Montluçon n'a jamais réussi à faire aboutir son plan. Une enquête pourrait être menée sur le rôle réellement joué par P. Constans dans l'élaboration de la loi car V. Claude, par exemple, ne l'évoque à aucun moment.

5. - MAROT, Gérard. La Loi du 14 mars 1919 et les plans d'aménagement, d'extension et d'embellissement des villes. Thèse pour le doctorat en sciences politiques et économiques, Poitiers, UFR de droit et sciences sociales. Poitiers : impr. moderne Nicolas, Renault et Cie, 1923, p. 4.

6. - Op. cit., p. 26.

7. - BONDE, Amédée. Traité pratique de l'aménagement, de l'extension, de l'embellissement des villes et des lotissements : lois des 14 mars 1919 et 19 juillet 1924 [...]. Paris : Dalloz, 1927, p. 10. La loi de 1924 s'attache particulièrement à régler les problèmes que pose la prolifération de lotissements défectueux.

8. - Au sujet du PAEE de Néris-les-Bains, en 1921, Louis Bonnier encourage le recul d'alignement imposé de $3 \mathrm{~m}$, car : «Indépendamment des plantations qu'il sera [...] possible de faire [...], on pourra obtenir, sans acquisition supplémentaire de terrains, de véritables allées fleuries tout au long de chaque rue ». CAC Fontainebleau, versement 19790426, art. 47.

9. - Ces monuments étaient pleinement reconnus depuis peu d'années : rappelons que la loi relative aux monuments historiques date du 31 décembre 1913.

10. - FENESTRE, Fabien. La notion d'aménagement et de composition urbaine dans les documents d'urbanisme - Retour sur un siècle d'évolution. DESS MSPCP, IEP de Lyon, université Lumière Lyon 2, mai-septembre 2002, URL : http://doc.sciencespo-lyon.fr/Ressources/Documents/Etudiants/ Memoires/Cyberdocs/MSPCP/fenestref/these.html [consulté le 18/12/2014]. Ces chiffres sont comparables à ceux donnés notamment par Viviane Claude.

11. - Exercice que Viviane Claude appelait de ses vœux.

12. - ESTIENNE, Pierre. Villes du Massif central. [Paris] : PUF (coll. « Institut de géographie », XXV), 1963.

13. - JAMOT, Christian. « Villes et morphologie urbaine en Auvergne ». Art. cit..

14. - FABRE, Xavier. «Aux villes du centre ». Dans TARRAGO, Llibert (dir.). Massif central. L'esprit des Hautes Terres. Paris : éditions Autrement, 1996, p. 158-167.

15. - AD Puy-de-Dôme, série $M$ : Administration départementale (1800-1940). Plus précisément, les fonds qui concernent les PAEE sont conservés en "police administrative», section 
« urbanisme ». En 2009, ce fonds était en cours de classement, après avoir été nourri d'archives auparavant classées en série $O$ (Administration et comptabilité communales).

16. - Viviane Claude avait déjà noté : «L'expertise de l'Association pour le développement de l'histoire de l'urbanisme fait apparaître les difficultés d'un tel travail [les recherches au niveau local] : problèmes d'accès, de conservation et de classement notamment ». Op. cit., p. 11. Que Frédérique Hamm, au Centre des archives contemporaines de Fontainebleau, Jean-Charles Forgeret, à la médiathèque du Patrimoine, Édouard Bouyé, aux archives départementales du Cantal, Henri Hours, Patrick Cochet, Françoise Chabrot et Fabienne Chazarin, aux archives départementales du Puy-de-Dôme, Véronique Boissadie-Villemaire, aux archives municipales de Cusset, Marie-Laure Pucenot, aux archives municipales de Commentry, Mme Goudon aux archives municipales de Bellerive-sur-Allier, Mme Bicard de la mairie de Saint-Yorre, Mme Magimel de la mairie de Royat, Mme Vigier de la mairie de Châtel-Guyon, le service des archives municipales de Clermont-Ferrand, D. Chagniaud aux services techniques de Clermont-Ferrand, soient ici remerciés pour avoir facilité mon travail.

17. - Soutenue en 1927, conservée sous ces références: 1927 (15) DESCOUTURES, Jean. "Aménagement et extension d'une station thermale dans le bassin de Vichy: Bellerive-surAllier », 2 vol., GRÉBER [Jacques Gréber, président du jury de thèse]. Je remercie Béatrice Perruchot, de l'Institut d'urbanisme de Paris, pour son efficacité.

18. - En sachant que parfois les plans qui nous intéressent sont conservés par les services techniques de la Ville (c'est le cas à Clermont-Ferrand, en plus d'un double, aux couleurs plus fraîches, conservé au Centre des archives contemporaines de Fontainebleau) ou à la médiathèque (c'est le cas de Vichy).

19. - Commentry, Montluçon, Moulins, Vichy (Allier); Aurillac (Cantal); Le Puy (Haute-Loire) ; Clermont-Ferrand, Riom, Thiers (Puy-de-Dôme).

20. - Cusset, Saint-Yorre (Allier) ; Aubière, Beaumont, Ceyrat, Issoire, Saint-Éloy-les-Mines (Puyde-Dôme).

21. - Bourbon-l'Archambault, Néris-les-Bains (Allier); Chamalières, Châtel-Guyon, Le Mont-Dore, Royat, Saint-Nectaire (Puy-de-Dôme).

22. - Durtol (Puy-de-Dôme) et Le Chambon-sur-Lignon (Haute-Loire). Le Chambon ayant été plutôt reconnue sur certains documents comme station de tourisme, elle n'était alors pas assujettie à la confection d'un plan.

23. - La Bourboule (Puy-de-Dôme). Toutes les stations classées (thermales, climatiques, touristiques ou mixtes) ne figurent pas forcément sur la liste dressée par le Conseil général des agglomérations tenues de se munir d'un « projet Cornudet ».

24. - Bellerive-sur-Allier (Allier); Neussargues, Riom-ès-Montagnes (Cantal). La disposition n'existait pas avant la modification de 1924. Citons le cas d'Aubière (Puy-de-Dôme), qui réclamait son inscription sur la liste en 1921, n'était pas retenue par le préfet car il estimait que la population, inférieure à 5000 habitants, ne permettait d'inscrire Aubière dans aucune des catégories de villes, et obtint gain de cause en 1927 par son insertion dans la catégorie « en voie d'accroissement".

25. - En 1937 Murols se sentait pourtant visée par la loi en demandant les barèmes des subventions qui lui seraient accordées, demande à laquelle il n'a pas été donné suite car elle ne figurait pas sur la liste établie par la commission départementale. De même que la localité d'Augerolles (débouté en 1931, le conseil municipal décide malgré tout en 1938 de faire établir un plan d'aménagement, « ceci dans le but de rendre la localité plus coquette, plus attirante aux étrangers et plus commode aux habitants ", en "considérant que le tourisme est une ressource essentielle des campagnes ») (AD Puy-de-Dôme, M 60856).

26. - Les dossiers de quatre des huit agglomérations ayant abouti émanent des stations thermales, soit la moitié des plans approuvés pour l'Auvergne, ce qui correspond au ratio 
national signalé par Gaston Bardet en 1939 dans un article intitulé «Vingt ans d'urbanisme appliqué ", publié dans la revue Architecture d'aujourd'hui (n³, p. 2-3).

27. - AN, F/2/2951. Et voir tableau récapitulatif en annexe.

28. - À Cusset, la date de la commande de projet est connue : 1928 ; les plan et programme datent de 1933, le passage en Commission supérieure a lieu en 1935, la déclaration d'utilité publique est obtenue en 1936.

29. - AD Puy-de-Dôme, O 02030, Communes astreintes à un plan : Riom (1936-1939), courrier du 18 octobre 1935. Le 31 août 1936, le conseil municipal décide de dix-huit "grands travaux » à faire figurer dans le projet d'embellissement et d'extension de la ville mais aucun autre élément n'a été retrouvé concernant ce dossier.

30. - Le $1^{\mathrm{er}}$ mars 1921 est débattue en conseil municipal la question de l'aménagement de la place de la République : à aucun moment il n'est question du texte de loi ou d'un plan d'ensemble de la ville. C'est l'architecte-voyer J. Eydieux qui en est chargé et présente plan et rapport (AM Issoire, $1 \mathrm{D} 12)$.

31. - AM Saint-Yorre, registre des délibérations du conseil municipal (12/6 et 2/12/1927, 3/11/1928;21/6/1930, 26/1/1933, 8/5/1934).

32. - Même si en 1925 le maire de Thiers, à la demande d'ouverture d'une rue, répond « que la rue à ouvrir sera comprise dans un projet d'ensemble comportant extension et embellissement de la ville » (AD Puy-de-Dôme, registre numérisé des délibérations du conseil municipal, 22/2/1925).

33. - AM Le Chambon-sur-Lignon, registre des délibérations du conseil municipal, 10/6/1922 ; AD Haute-Loire, 8 M 44.

34. - AM Moulins, registre des délibérations du conseil municipal, $n^{\circ} 52$.

35. - Le maire de Royat écrit en 1924 au préfet : « il est souvent plus facile de faire une loi que de la faire appliquer $»$.

36. - Courrier : réponse du préfet au ministre du 28 mai 1940 (AD Puy-de-Dôme, M 60834).

37. - Les plans proposés sont conservés aux archives municipales de la ville : le «Plan général de Montluçon établi en application de la loi du 14 mars 1919 » (de l'architecte Talbourdeau) daté de 1921 en série $1 \mathrm{~T}$ 1/2, le "plan général d'extension et d'aménagement » (Topoplan et l'ingénieur Auclair) daté de 1926 en 1 T 1/3, le plan de 1934 en série 4 Fi 4/13 et le plan de zonage de 1936 en série $1 \mathrm{~T} 1 / 1$ (tous les deux de l'Office technique des ingénieurs spécialistes).

38. - CAC Fontainebleau, versement 19790426, art. 41.

39. - Des incertitudes subsistent quant à la date de création de la société. Dans l'ouvrage paru en 1915 et 1916 chez Armand Colin, Comment reconstruire nos cités détruites. Notions d'urbanisme s'appliquant aux villes, bourgs, villages, signés des architectes Donat Alfonse Agache (architecte du Musée social et secrétaire général de la SFAU), Marcel Auburtin et Édouard Redont, la société est annoncée comme ayant été fondée en 1913.

40. - Topoplan pour Cusset, Montluçon, Bellerive-sur-Allier et Saint-Nectaire (dans les deux derniers cas, documents signés plus précisément de Jean Descoutures, ingénieur-urbaniste, ancien élève de l'Institut d'urbanisme, qui a œuvré aussi ailleurs en France, à Saint-Cast, Côtesd'Armor, en 1932, par exemple), Jean Descoutures à nouveau pour le $2^{\mathrm{e}}$ plan du Puy-en-Velay, Topoplan en la personne de A. Pontabry, pour le relevé topographique seulement, à Montluçon, qu'utilisera plus tard la société OTIS (office technique d'ingénieurs spécialistes), et l'Union urbaniste pour Le Mont-Dore (qui se substitue à l'urbaniste Léon Jaussely) et pour Aurillac, en ce cas, en la personne de l'architecte Maurice Fournier qui signe « délégué du bureau technique des plans de villes ", associé à l'architecte départemental Croizet et à l'ingénieur municipal Terrisse : voir les termes $\mathrm{du}$ «traité avec l'union urbaniste » retranscrit dans le registre des délibérations du conseil municipal (AM Aurillac, 6 juin 1924).

41. - Les architectes Talbourdeau père et fils, de Montluçon, puis Mitton de Clermont-Ferrand, pour Bourbon-l'Archambault ; Talbourdeau (père ou fils ?) pour un premier essai pour leur ville ; Nuret, de Commentry, pour sa ville; Mazon, de Vichy, pour la sienne. De l'architecte Paul 
Neyrial, associé aux ingénieurs Sens-Cazenave, Pouliquen et Bonnefont, pour La Bourboule, l'origine n'est pas connue. L'architecte Georges Galinat, de Riom, associé à l'ingénieur géomètre Sarrou, pour Châtel-Guyon. Les géomètres Weissbrodt, de Montluçon (formé dans l'agence des géomètres et urbanistes des frères Danger), pour Aubière, et Maurice Lombardy, installé à Vichy puis à Riom, pour Durtol et Riom. À la suite de l'architecte Talbourdeau qui n'a pas donné satisfaction à Montluçon, commande sera passée à l'ingénieur T.P.E. et directeur du service de voirie de la Ville Aimé Auclair (qui ne donnera pas non plus satisfaction et qui sera remplacé par la société francilienne OTIS, qui elle non plus ne permettra pas à la ville d'obtenir sa DUP !). Les ingénieurs Mercier, de Montluçon, pour Néris-les-Bains ; Vaurs, Férérol et Bergoin pour Royat et Chamalières (on ne connaît pas les adresses professionnelles des deux derniers), les deux premiers et Renard, ingénieur du service vicinal de Beaumont, pour Beaumont, auxquels sont associés, pour le relevé topographique, les géomètres-urbanistes Danger, de Paris (un des frères Danger étant membre de la Commission supérieure des plans de villes) ; les ingénieurs-voyers I.A. Passignat, à Vichy, avant qu'on ne fasse appel à l'architecte Mazon, et Lavilatte, pour l'avantprojet de Moulins ; l'architecte de la Ville A. Proy au Puy-en-Velay pour la première tentative, remplacé ensuite par le Parisien J. Descoutures; à Clermont-Ferrand, l'ingénieur municipal J. Morel a dirigé le personnel technique municipal.

42. - Les rapporteurs de la Commission supérieure ayant eu à traiter des dossiers en Auvergne sont principalement Charles Letrosne, Louis Bonnier et André Bérard, mais aussi René Danger et P. Normand. Parmi les rapporteurs de la commission départementale du Puy-de-Dôme, on trouve l'architecte départemental Ernest Pincot, l'ingénieur en chef de la Ville de Clermont-Ferrand Morel, l'ingénieur en chef des Ponts et Chaussées Hennequin et l'ingénieur en chef du service vicinal (de Clermont ou de Chamalières, nous n'avons pu le déterminer) Vaurs.

43. - Rapport de L. Bonnier du 15 février 1938 au sujet de Montluçon (CAC Fontainebleau, versement 19770084, art. 40).

44. - Rapport de A. Bérard, non daté (CAC Fontainebleau, versement 19790426, art. 41). On peut consulter la proposition critiquée de l'architecte Nuret aux AM de Commentry, série 3 D 1 (plans).

45. - Je remercie Fabienne Gelin de me l'avoir signalé. «Plan d'extension et d'embellissement de la ville de Vichy ", daté du 14 mars 1928, signé de l'ingénieur-voyer I. A. Passignat, non coté. Par ailleurs, il a été vérifié que le plan de Mazon n'était pas conservé non plus dans les archives de la Compagnie de Vichy, ancienne Compagnie fermière.

46. - Il reste qu'au moins deux aspects du projet ont été réalisés (la grande "allée de $40 \mathrm{~m}$ » bordée d'arbres, actuelle allée des Ailes, et le dégagement de la place du Catalpa). Il faudrait en trouver l'explication exacte mais Letrosne nous apprend dans son rapport de 1930 que «la solution de quelques questions d'urbanisme » devenait urgente pour la ville, laissant entendre que certains aménagements avaient déjà été évoqués et que le plan de Passignat ne faisait que leur donner forme à l'échelle d'un plan de la totalité de la ville.

47. - Rapport de C. Letrosne du 4 décembre 1930, rapport de A. Bérard du 20 mai 1938 (CAC Fontainebleau, versement 19790426, art. 49).

48. - Gaston Bardet avait été investi de la mission de produire un plan pour le "Grand Vichy » par décision préfectorale du 5 mars 1942 mais un plan des «Promenades et parcs" autour de Vichy avait été établi par lui à la demande de la Société des sciences médicales, et publié dans la revue Architecture d'aujourd'hui en 1939 ( $\mathrm{n}^{\circ} 3$ ) parmi plusieurs PAEE (CAC Fontainebleau, versements 19770084, art. 40 et 19790426, art. 49).

49. - Délibération du conseil municipal du 20 avril 1939 (AD Puy-de-Dôme, M 60832). En l'occurrence, la comparaison du plan de 1874 avec le plan proposé par Weissbrodt est éloquente : le saut en matière de hardiesse est gigantesque.

50. - Clermont-Ferrand, plan d'aménagement et de reconstruction, 1945-1964 (AD Puy-de-Dôme, 1639 W 6). 
51. - AM Beaumont, plans d'alignement, non cotés. Je remercie Christophe Laurent pour son aide.

52. - CAC Fontainebleau, versement 19810400, art. 206.

53. - AM Aurillac, registre des délibérations du conseil municipal, 6/6/1924.

54. - « Ce plan est en effet inapplicable - voirie immense et ruineuse, réalisations trop grandioses - et n'a jamais été suivi » (CAC Fontainebleau, versement 19790426, art. 378).

55. - CAC Fontainebleau, versement 19790426, art. 49.

56. - AD Puy-de-Dôme, M 60841.

57. - Voir à Beaumont, délibération du conseil municipal du 4 novembre 1937.

58. - Registre des délibérations du conseil municipal, 17 décembre 1922 (AM Néris-les-Bains, 1 D 7).

59. - Voir RENAUD-MORAND, Bénédicte. Les villes en Auvergne, fragments choisis. Lyon : Lieux dits éd. ( Cahiers du patrimoine ", n¹09), 2014, p. 116-118.

60. - Avant qu'une grande partie du parc ne soit à nouveau occupée par le nouvel établissement de soins et de loisir et par un parc de stationnement.

61. - Document remis le 28 mars 1925 (AD Puy-de-Dôme, M 60858).

62. - Conservé au Centre des archives d'architecture du $x^{e}$ siècle, fonds Léon Jaussely, JAUSSC-26-2, collections Académie d'architecture, Paris. Dossier 312 AA 10/11. Ce PAEE n'est pas daté. Voir : RENAUD-MORAND, Bénédicte. Les villes en Auvergne, fragments choisis. Lyon : Lieux dits éd. ( Cahiers du patrimoine », $n^{\circ} 109$ ), 2014, p. 110-113 (et notamment la figure 154). On peut noter que sur cette version du PAEE figurent deux avenues qui font partie des rares aménagements réalisés au Mont-Dore entre 1919 et 1930. Voir CERONI, Brigitte, FIZELLIER-SAUGET, Bernadette, LAFONT, Annie, et al. Le Mont-Dore, une ville d'eaux en Auvergne. Op. Cit., p. 12.

63. - AD Puy-de-Dôme, M 60846.

64. - Courrier daté du 24 avril 1931 (CAC Fontainebleau, versement 19810400, art. 211).

65. - Registre des délibérations de la commission départementale (1929-1939), séance du 25 janvier 1930 (AD Puy-de-Dôme, M 60855).

66. - Extrait du registre des délibérations du conseil municipal, 25 avril 1935 (AD Haute-Loire, 157 O XI).

67. - Les fonds des archives municipales, des archives départementales de la Haute-Loire et du centre de Fontainebleau n'ont livré aucune des versions du PAEE du Puy. Ces «Observations » datées du 21 juin 1922 ont été publiées dans le Bulletin historique, scientifique, littéraire, artistique et agricole de la Haute-Loire, t. VII, 1922, p. 345-364.

68. - Voir CHOAY, Françoise. Le patrimoine en question. Paris : Seuil (La couleur des idées) 2009, p. 167-176.

69. - Voir ROSSI, Aldo. L'architecture de la ville. Gollion : InFolio (Archigraphy), 2001 (1 ère éd. 1966). 70. - Voir CUSSINET, Marie-France. «Fécond et éclectique XIXe siècle ». Dans MARTIN, Daniel (dir.). L'identité de l'Auvergne : mythe ou réalité historique [...]. Nonette : Créer, 2002, p. 596-603.

71. - Voir ESTIENNE, Pierre. Villes du Massif central. Op. cit. Les buttes et les pentes sur lesquelles églises et châteaux s'étaient implantés sont probablement à l'origine de ce phénomène. La thèse des éléments premiers est bien illustrée à Clermont-Ferrand : en 1944, la mairie avait confié aux architectes Jarrier et Depailler le projet de faire descendre l'hôtel de ville sur la place de Jaude, le nouveau centre de commerce sur lequel s'ouvrent plus ou moins directement la préfecture et le théâtre municipal (reconstruit sur une halle); Gaston Bardet avait donné son avis sur les deux propositions (implantation au centre de la place sur un terre-plein, ou bien au nord) et donner de manière argumentée la sienne (à l'est de la place). Mais on constate aujourd'hui que l'hôtel de ville est resté fixé au sommet de la butte, d'une part à proximité directe de la cathédrale, d'autre part à l'emplacement du palais de Boulogne où la Cour des aides, la prison et le tribunal se trouvaient depuis le XVII ${ }^{\mathrm{e}}$ siècle, ensemble sur lequel l'hôtel de ville avait été reconstruit à partir de 1822. 
72. - Avec ce défaut pour Néris-les-Bains de n'en connaître qu'une version publiée en noir et blanc, alors que les PAEE ont pour particularité d'indiquer grâce à un code de couleurs les propositions de création et de modification sur un état des lieux. Ce code est d'ailleurs le même que pour les plans d'alignement auxquels étaient assujetties certaines villes françaises en vertu de la loi du 16 septembre 1807, inscrivant en quelque sorte la loi de 1919 dans une filiation des lois traitant de voirie urbaine. Le plan de Néris, signalé dans GRENIER, Lise (dir.). Villes d'eaux en France. Paris : Hazan, 1985, comme étant conservé au Centre des archives contemporaines de Fontainebleau, serait retourné depuis 1984 au ministère de l'Équipement. Pour Châtel-Guyon, on dispose de deux plans différents : l'un du 14 août 1929, portant la mention « vu pour être annexé au décret du 17 février 1931 »(AD Puy-de-Dôme, M 60835), et l'autre, publié dans l'ouvrage dirigé par Lise Grenier précédemment cité, daté de 1930 et donné comme issu du fonds de la DDE du Puy-de-Dôme, et semblant tenir compte d'une modification décidée en conseil municipal le 26 octobre 1929.

73. - DUBOY, Philippe. «Vingt ans d'urbanisme appliqué ». Dans GRENIER, Lise (dir.). Op. cit.. TOULIER, Bernard. «Les réseaux de la villégiature en France ». In Situ, revue des patrimoines [en ligne], 4/2004, mis en ligne le 01 mars 2004, consulté le 09/04/2010.<URL: http:// insitu.revues.org/1348>. TOULIER, Bernard. « De la ville régulière à la ville paysagère. [...] ». Revue de l'art, $\mathrm{n}^{\circ} 165,2009$, p. 9-18.

74. - Reconduction au sens de comparaison entre le plan du projet et le plan cadastral actuel de façon à mesurer ce qui a été réalisé.

75. - Pour un bilan plus détaillé des opérations réalisées à Clermont-Ferrand, voir ANTONIO, Marcel. Urbanisme et société à Clermont-Ferrand de 1918 à 1939. Clermont-Ferrand : ADIC, 1984. Tout en étant averti par l'auteur qu'il n'a pas cherché dans son travail à donner « une description minutieuse et exacte de toutes les réalisations urbaines opérées dans la ville, mais une tentative de compréhension du mécanisme urbain dans la perspective «d'Economie et Société dans le Massif central » $»($ p. 6).

76. - Note du 19 octobre 1926 (AD Puy-de-Dôme, M 60857).

77. - CAC Fontainebleau, versement 19790426, art. 47. Sur l'apparition de la notion de «paysage urbain », voir JANNIÈRE, Hélène. « De l'art urbain à l'environnement : le paysage urbain dans les écrits d'urbanisme en France, 1911-1980». Strates [En ligne], 13/2007, mis en ligne le 22 octobre 2008, consulté le 09/04/2010 <URL : http://strates.revues.org.5223>. L'auteur y déclare d'ailleurs : «Il faudrait prolonger ce corpus par les écrits accompagnant les Plans d'aménagement, d'embellissement et d'extension (PAEE) à partir de 1919 ».

78. - Institut d'urbanisme de Paris, fonds historique, cote 1927 (15), non paginé.

79. - Rapport de Charles Letrosne, 24 juillet 1931 (CAC Fontainebleau, versement 19790426, art. 41).

80. - Rapport de la Commission supérieure du [18 juin] 1926 (AD Puy-de-Dôme, M 60857).

81. - Et qui forme avec son prolongement de la rue Blatin «l'une des plus belles et des plus vivantes artères de l'agglomération clermontoise ». Tiré du Mémoire explicatif du PAEE de Chamalières (1930) (AD Puy-de-Dôme, M 60846).

82. - Mémoire explicatif pour le projet de Beaumont (1939) (AD Puy-de-Dôme, M 60834). Mémoire explicatif pour le projet de Chamalières (1930) (AD Puy-de-Dôme, M 60846). Mémoire explicatif pour le projet de Royat (1931) (AD Puy-de-Dôme, M 60842, et aussi, AM Royat, 3 T 1).

83. - Cité par Françoise Choay dans Le patrimoine en questions. Paris : Seuil, (La couleur des idées), 2009, p. 163.

84. - Avis du 13 février 1937 (AM Montluçon, 1 T1/2).

85. - Rapport du 3 avril 1930 (AD Puy-de-Dôme, M 60835).

86. - DANGER, René. Cours d'urbanisme. Paris : Léon Eyrolles, 1933.

87. - Rapport du 11 janvier 1934 (AD Puy-de-Dôme, M 60842).

88. - Registre des délibérations municipales, $n^{\circ} 52,18$ mars 1922 (AM Moulins). 
89. - La formule résonne dans une phrase de l'urbaniste Élie Mauret, au sujet d'un aménagement datant de 1958 à Aurillac: «Il serait en effet regrettable qu'à l'occasion de l'ouverture d'un boulevard nouveau, des constructions soient implantées banalement de part et d'autre de ce boulevard».

90. - MAROT, Gérard. La Loi du 14 mars 1919... Thèse citée, p. 2.

91. - Mémoire-programme (1933) (AD Puy-de-Dôme, M 60841). Dans cette optique, Jean Descoutures poursuivait: "ne jamais chercher à copier la grande ville comme le font inconsciemment tant de stations thermales qui tombent ainsi dans la plus décevante banalité ». Dans le même souci de «ne pas faire ville» mais lieu de villégiature, Charles Letrosne recommandait, pour Royat, de diminuer la hauteur règlementaire des immeubles, surtout « dans le Royat-thermal ».

92. - D'après l'architecte et théoricien anglais Raymond Unwin (1863-1940), la récurrence des points de vue en ville est une spécificité française.

93. - AM Clermont-Ferrand, $913 \mathrm{~W} 1$.

94. - « Il faut donc déboucher le «fond de Jaude » actuel qui doit être remplacé par une vue sur les montagnes» (CAC Fontainebleau, versement 19810400, art. 213). On peut apprécier aujourd'hui, par la négative, la pertinence de son expertise.

95. - Zone de protection du patrimoine architectural, urbain et paysager.

96. - SEMMOUD, Nora. «Stratégies urbaines». Dans CERAMAC. L'Auvergne urbaine. Op. cit., p. 201-230.

97. - AM Clermont-Ferrand, 913 W 1. Ce qui est bien différent de ce qui était annoncé en 2000 dans le document de présentation de la révision du POS : "Clermont-Ferrand bénéficie d'un environnement naturel de grande qualité, qui doit être préservé d'une urbanisation diffuse et désordonnée. Proches du territoire urbain, les Côtes de Clermont, de Vallières et le puy de Crouël sont des espaces déterminants de notre qualité de vie. Leur valorisation est l'une des caractéristiques introduites dans le POS révisé, qui interdit toute construction nouvelle ».

98. - Registres des délibérations du conseil municipal (AM Riom-ès-Montagnes). La demande d'assujettissement avait été décidée le 12 décembre 1926 mais le 13 janvier 1929, la ville semble avoir quelque difficulté financière pour monter le dossier puisqu'elle lance une «demande de subvention au ministère pour la confection de ce volumineux dossier ». Les démarches pour être classée "en voie d'extension " sont encore en cours au 8 septembre 1929. On sait aussi, à la lecture des délibérations, qu'il était reproché au maire de l'époque de s'attacher au programme de voirie au détriment de l'exécution du réseau d'égouts.

99. - Rapport sur divers projets de lotissements, 12 juin 1925 (AD Puy-de-Dôme, M 60853).

100. - Sur l'insertion des lotissements Michelin au sein du plan de Clermont-Ferrand, voir ANTONIO, Marcel. Op. cit., et aussi : LUNEAU, Jean-François. «La Cité «La Plaine » à ClermontFerrand ». Dans CUSENIER, Jean (dir.). Matière et figure. Paris : Documentation française, 1991, p. 47-71. Enfin, voir l'examen des demandes d'autorisation par la commission départementale (AD Puy-de-Dôme, M 60855).

101. - En témoigne aussi, à l'extérieur des frontières auvergnates, un concours d'idées pour l'extension et l'embellissement de Dunkerque qui avait été lancé dès 1912 par une société savante locale. Voir BRUANT, Catherine. «Donat Alfred Agache (1875-1959). L'urbanisme, une sociologie appliquée ». Dans BERDOULAY, Vincent et CLAVAL, Paul (dir.). Aux débuts de l'urbanisme français. Regards croisés de scientifiques et de professionnels (fin XIXe-début XXe siècle). Paris : L'Harmattan, 2001, p. 133-150. De même qu'à Lyon où, d'après l'ingénieur montluçonnais Aimé Auclair, un plan d'aménagement et d'extension avait été dressé dès 1912 (et exposé à Strasbourg pour le congrès international d'Urbanisme). Courrier du 20 novembre 1926 et rapport du 23 mai 1928 (AM Montluçon, $1 \mathrm{~T} \frac{1}{2}$ ).

102. - Un exemplaire du rapport est conservé à la médiathèque de Vichy, dans les fonds patrimoniaux, sous la cote V 10711.4 RIC. 
103. - « Dossier urbain » de M. Lombardy, du 5 janvier 1931 (AD Puy-de-Dôme, M 60836).

104. - Rapport de Louis Bonnier du 15 décembre 1929 (CAC Fontainebleau, versement 19770084, art. 40).

105. - Rapport de Charles Letrosne du 4 décembre 1930 (CAC Fontainebleau, versement 19790426, art. 49).

106. - ANTONIO, Marcel. Op. cit., p. 310-311.

107. - Rapport du 13 décembre 1929 (AD Puy-de-Dôme, M 60835).

108. - Texte d'une conférence dont le sujet est l'analyse du PAEE d'Aurillac, non publié mais aimablement communiqué par Vincent Flauraud, maître de conférences à l'université BlaisePascal de Clermont-Ferrand.

109. - À partir de 1932, date d'une note du ministère de l'Intérieur, le zonage exigé concerne prioritairement les limites entre industries et habitations.

110. - Sur cette question, voir CLAUDE, Viviane. «Une solution pratique aux problèmes urbains aux débuts du Xx $x^{\mathrm{e}}$ siècle ». Annales des Ponts et Chaussées, janvier-mars 2000, n93, p. 23-29.

111. - C'est la réponse du conseil municipal à la question posée par la commission départementale quant à l'absence de servitudes esthétiques (AD Puy-de-Dôme, M 60855, séance du 30 juillet 1925).

112. - AM Clermont-Ferrand, $913 \mathrm{~W} 1$. Inversement, des demandes de conseils provenant de Royat, Limoges, Arcachon, Montpellier et Tlemcen sont parvenues à Clermont.

113. - MINNAERT, Jean-Baptiste. «Les phénomènes du péri-urbain: territoires et réseaux, recherche et opérationnel ». Dans Conseil national de l'inventaire général du patrimoine culturel, procès-verbal de la séance $d u$ 10/12/2008 [En ligne], p. 18-20, URL: http:// www.inventaire.culture.gouv.fr/.

114. - La servitude de «physionomie locale » d'Aubière (1938-1939) semble directement inspirée de l'ouvrage de René Danger, cité plus haut, p. 202.

115. - BARDET, Gaston. Problèmes d'urbanisme. Paris : Dunod, 1948, p. 170.

116. - «Observations » datées du 21 juin 1922 publiées dans le Bulletin historique, scientifique, littéraire, artistique et agricole de la Haute-Loire, t. VII, 1922, p. 345-364.

117. - Ladite maison aurait été démolie en deux temps : une première partie destinée à libérer un passage vers 1900, puis, le passage se révélant trop étroit, le conseil municipal aurait décidé sa démolition totale. Voir ANTONIO, Marcel. Op. cit., p.343-344. Mais il faudrait vérifier le déroulement du processus puisque le PAEE de Clermont daté de 1925 porte un bâtiment en jaune (c'est-à-dire "à démolir ») à l'endroit où l'on situe habituellement la maison de Pascal. Il faut aussi ajouter qu'avec le dégagement du chevet de la cathédrale, le PAEE reprend une proposition d'un plan d'alignement datant de 1821.

118. - Rapport du 19 octobre 1926 (AD Puy-de-Dôme, M 60857).

119. - Plan de sauvegarde et de mise en valeur.

120. - Zone de protection du patrimoine architectural, urbain et paysager.

121. - En 1930, l'ordre du jour des séances de la Commission supérieure des PAEE est transmis aux Monuments historiques. En 1936, les architectes en chef des Monuments historiques sont priés de fournir la liste des édifices classés et inscrits situés dans les villes dont les projets sont examinés. En 1939, quatre rapporteurs issus du domaine des Monuments historiques doivent être désignés pour intervenir dans les Commissions supérieures des PAEE. La Commission supérieure des monuments historiques avait parmi ses missions de donner son avis sur les propositions de classement de communes en station touristique, de même que sur la prorogation à l'autorisation de percevoir une taxe de séjour (dont il pouvait être demandé qu'elle soit affectée à l'entretien des édifices anciens).

122. - CAC Fontainebleau, versement 19790426, art. 47. Cité par L. Bonnier dans son rapport du 21 mars 1921. 
123. - Pour des exemples particuliers externes à l'Auvergne, on peut consulter, sur Pau : PUYO, Jean-Yves. «Les premiers temps de la planification urbaine paloise : l'héritage méconnu des années 1920 à 1940 ». Dans BIDOT-GERMA, Dominique (dir.). Mémoires de Pau, 2011. Pau : éd. Cairn, p. 114-129. Pour Rennes, on pourra se reporter soit à la notice «Urbanisme: plan d'aménagement, d'extension et d'embellissement " à l'adresse: http://patrimoine.regionbretagne.fr/, soit à : BARBEDOR, Isabelle, et al.. Rennes, mémoire et continuité d'une ville. Paris : Monum - éditions du Patrimoine (Cahiers du patrimoine, $\mathrm{n}^{\circ}$ [69]), 2004, p. 59-65.

124. - AM Le Puy-en-Velay, dossier non coté intitulé «Urbanisme - Projet d'aménagement, d'embellissement et d'extension - 1922 ».

125. - Registre de délibérations du conseil municipal, AM Châtel-Guyon.

126. - « Rapport en réponse au questionnaire posé par la commission supérieure d'aménagement, d'embellissement et d'extension des villes, dans sa séance du 12/1/1934 ", signé des trois ingénieurs Vaurs, Férérol et Bergoin, daté du 28 juin suivant (AD Puy-de-Dôme, M 60842).

127. - Jean-Marie Pérouse de Montclos signale souvent le danger des restitutions graphiques d'édifices car elles inspirent immanquablement les projets de restauration des architectes des Monuments historiques!

128. - Rapport justificatif des principes du plan directeur, 18 juin 1946 (AD Puy-de-Dôme, 1639 W $6)$.

129. - AM Clermont-Ferrand, $896 \mathrm{~W} 1$.

130. - Société centrale pour l'équipement du territoire. Dix ans de plans-masse; analyse comparative. Paris : SCET, sans date [1969], p. 54.

\section{RÉSUMÉS}

La loi promulguée en 1919, complétée en 1924, qui oblige certaines villes à se doter d'un Plan d'aménagement, d'embellissement et d'extension, dite loi Cornudet, s'impose comme l'ancêtre des lois de planification urbaine en France. Cinq types de villes étaient visés sur le territoire national. En Auvergne, 29 répondent aux critères de quatre des cinq types. Nous avons tenté de mettre en évidence les traces de l'application de cette loi dans ces 29 villes, et de faire émerger des fonds d'archives les débats auxquels elle a donné lieu entre instances nationales, autorités locales et habitants. Certaines municipalités se sont montrées très volontaires, d'autres beaucoup plus timides, voire récalcitrantes. Dans le cadre de l'enquête publique, certains habitants se sont beaucoup exprimés, d'autres sont restés indifférents.

The so-called 'Cornudet' law of 1919, amended in 1924, which obliged certain towns to provide themselves with plans for their future extension, improvement and development, may be regarded as the forerunner of French urban planning law. The law covered five types of towns across national territory. In Auvergne, 29 met the criteria set for four out of the five types. Attempts were made to show that the law was being applied in all 29 of the towns in question, with collections of archives assembled bearing witness to the discussion it had given rise to among national and local authorities and inhabitants. Some municipalities showed themselves eager to get down to work, while others were rather more hesitant, even reluctant. Some inhabitants taking part in public surveys had a good deal to say on the subject, while others seemed more or less indifferent. 


\section{INDEX}

Keywords : town-planning, development planning

Mots-clés : planification urbaine, plan d'aménagement, d'embellissement et d'extension (ou :

PAEE), Honoré Cornudet, Gaston Bardet, Louis Bonnier, Jean Descoutures, Topoplan,

Talbourdeau, Mitton, Nuret, Paul Neyrial, Georges Galinat, Léon Jaussely, Charles Letrosne, André Bérard, René Danger, Roger Puget, Bellerive-sur-Allier, Bourbon-l'Archambault, Commentry, Cusset, Montluçon, Moulins, Néris-les-Bains, Saint-Yorre, Vichy, Aurillac, Neussargues, Riom-èsMontagnes, Le Chambon-sur-Lignon, Le Puy-en-Velay, Aubière, Beaumont, Ceyrat, Chamalières, Châtel-Guyon, Clermont-Ferrand, Durtol, Issoire, La Bourboule, Le Mont-Dore, Riom, Royat, Saint-Éloy-les-Mines, Saint-Nectaire, Thiers

\section{AUTEUR}

\section{BÉNÉDICTE RENAUD}

Conservateur du patrimoine/chercheur. Service chargé de l'Inventaire général du patrimoine culturel, Région Auvergne-Rhône-Alpes benedicte.renaud@auvergnerhonealpes.eu 